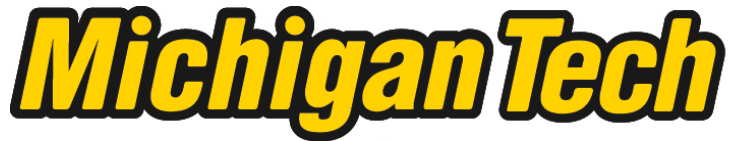 \\ Michigan Technological University Create the Future Digital Commons @ Michigan Tech
}

2013

Beech bark disease distribution and resistance in Michigan and fungal endophyte ecology of resistant and susceptible beech (Fagus grandifolia Ehrh.)

Rachel E. Griesmer-Zakhar

Michigan Technological University

Follow this and additional works at: https://digitalcommons.mtu.edu/etds

Part of the Other Forestry and Forest Sciences Commons, and the Plant Pathology Commons Copyright 2013 Rachel E. Griesmer-Zakhar

Recommended Citation

Griesmer-Zakhar, Rachel E., "Beech bark disease distribution and resistance in Michigan and fungal endophyte ecology of resistant and susceptible beech (Fagus grandifolia Ehrh.)", Master's Thesis, Michigan Technological University, 2013.

https://doi.org/10.37099/mtu.dc.etds/455

Follow this and additional works at: https://digitalcommons.mtu.edu/etds

Part of the Other Forestry and Forest Sciences Commons, and the Plant Pathology Commons 


\title{
BEECH BARK DISEASE DISTRIBUTION AND RESISTANCE IN MICHIGAN AND FUNGAL ENDOPHYTE ECOLOGY OF RESISTANT AND SUSCEPTIBLE BEECH (FAGUS GRANDIFOLIA EHRH.).
}

\author{
By \\ Rachel E. Griesmer-Zakhar
}

\begin{abstract}
A THESIS
Submitted in partial fulfillment of the requirements for the degree of MASTER OF SCIENCE

In Forest Ecology and Management
\end{abstract}

MICHIGAN TECHNOLOGICAL UNIVERSITY

2013

(C) 2013 Rachel E. Griesmer-Zakhar 
This thesis has been approved in partial fulfillment of the requirements for the Degree of MASTER OF SCIENCE in Forest Ecology and Management.

School of Forest Resources and Environmental Science

\author{
Thesis Advisor: Andrew J. Storer \\ Committee Member: $\quad$ Dana L. Richter \\ Committee Member: $\quad$ Thomas P. Snyder \\ Committee Member: $\quad$ Gerard C. Adams
}

School Dean: $\quad$ Terry L. Sharik 


\section{Table of Contents}

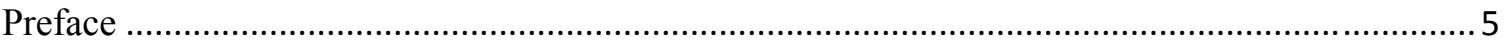

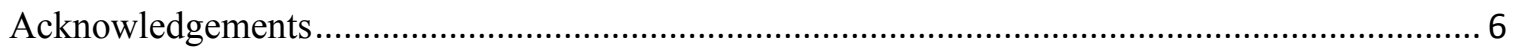



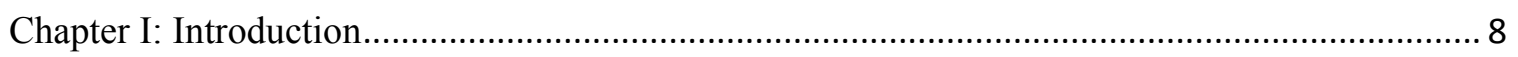

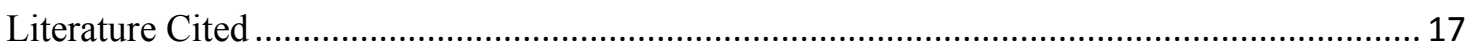

Chapter 2: Beech bark disease distribution and development in Michigan's Lower Peninsula. ... 24

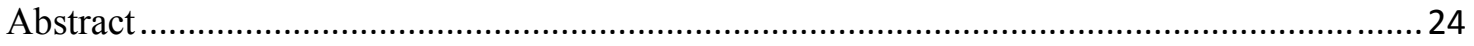

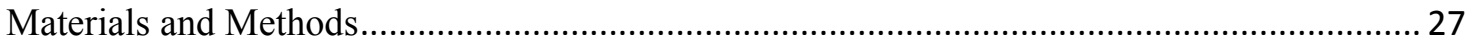

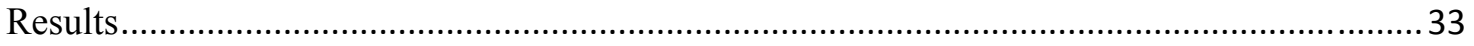

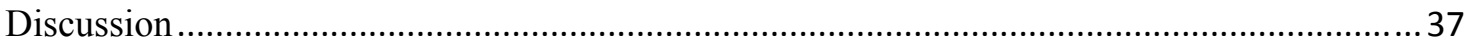

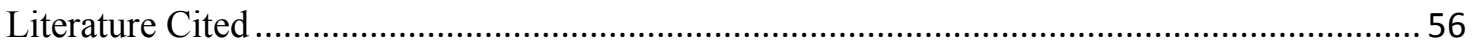

Chapter 3: Fungal endophyte incidence and potential function within American Beech (Fagus

grandifolia) and associated antagonism of Neonectria faginata ............................................... 59

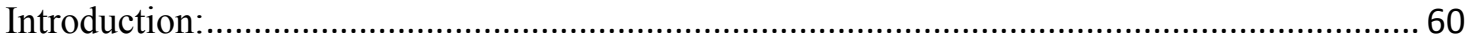

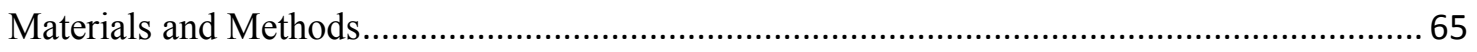

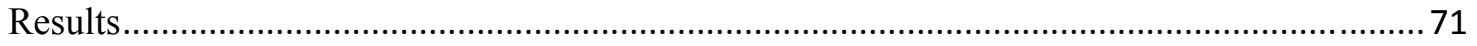

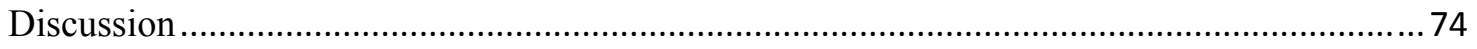

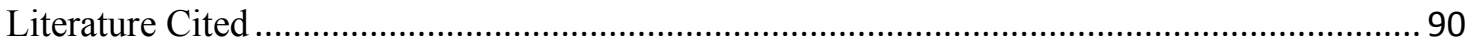




\section{Preface}

The original material presented in this thesis benefitted from the comments and advice of Andrew J. Storer, Dana L. Richter, Gerard C. Adams, Ann L. Maclean and Thomas P. Synder. Rachel Griesmer-Zakhar collected, entered, and analyzed data in addition to collection of any fungal samples and the maintenance of associated fungal cultures. Ann Maclean provided expertise and guidance in GIS-related analysis methods and interpretation. Gerard Adams and Dana Richter provided expertise in fungal endophyte identification and isolation methodologies. Jessie A. Glaeser extracted DNA and sequenced fungal endophyte isolates. 


\section{Acknowledgements}

This study would not have been possible if not for my advisor, Dr. Andrew J. Storer whom I can't thank enough for offering me this excellent opportunity which molded me into a more independent, scientific individual. I would like to thank Dr. Dana L. Richter for his ongoing, thoughtful support, encouragement, and kindness. I would like to thank Dr. Gerry Adams for introducing me to the wonderful world of forest pathology and leading me into the career path that I love. Thank you to my stalwart crew, Kristina Denison, Melissa Porter-Witkowski, Jordyn Denomme, Clara DeYoung, and Karl Larson for their great attitudes, enthusiasm and work ethic while in the field. Lastly I would like to thank my husband and my family for their unconditional support, advice, and assistance throughout the ups and downs of my graduate experience. 
Thesis Abstract - Beech bark disease (BBD), a non-native association of the fungal pathogen Neonectria faginata and the beech scale insect Cryptococcus fagisuga, has dramatically affected American beech within North American forests. To monitor the spread and effects of BBD in Michigan, a network of forest health monitoring plots was established in 2001 following the disease discovery in Ludington State Park (Mason County). Forest health canopy condition and basic forestry measurements including basal area were reassessed on beech trees in these plots in 2011 and 2012. The influence of bark-inhabiting fungal endophytes on BBD resistance was investigated by collecting cambium tissue from apparently resistant and susceptible beech. Vigor rating showed significant influences of BBD in sample beech resulting in reduced health and substantiated by significant increases of dead beech basal area over time. C. fagisuga distribution was found to be spatially clustered and widespread in the 22 counties in Michigan's Lower Peninsula which contained monitoring plots. Neonectria has been found in Emmet, Cheboygan and Wexford in the Lower Peninsula which may coincide with additional BBD introduction locations. Surveys for BBD resistance resulted in five apparently resistant beech which were added to a BBD resistance database. The most frequently isolated endophytes from cambium tissue were identified by DNA sequencing primarily as Deuteromycetes and Ascomycetes including Chaetomium globosum, Neohendersonia kickxii and Fusarium flocciferum. N. faginata in antagonism trials showed significant growth reduction when paired with three beech fungal endophytes. The results of the antagonism trial and decay tests indicate that $N$. faginata may be a relatively poor competitor in vivo with limited ability to degrade cellulose. 


\section{Chapter I: Introduction}

\section{Beech Bark Disease History}

Beech bark disease, a non-native complex between a scale insect and a pathogenic fungus in the genus Neonectria has dramatically changed American forests since its introduction to Halifax, Nova Scotia in the 1890s (Ehrlich, 1934; Shigo, 1964). The disease likely arrived on European beech, Fagus sylvatica L. nursery stock infested with beech scale (Cryptococcus fagisuga Lind.). Beech bark disease had been documented in Europe as early as 1838, apparently originating in south-eastern Europe on Fagus orientalis Lipsky (Houston et al., 1979b; Gwiazdowski et al., 2006). Disease cycles are similar in Europe and North America though impacts in Europe are less severe. The three arbitrary stages of beech bark disease have been described as the advancing front, killing front and aftermath zone (Shigo, 1972). The advancing front is characterized by early populations of beech scale with low levels of BBD-induced mortality. The introduction and proliferation of Neonectria typify the killing front which lags 3-6 years behind the scale insect (McCullough et al., 2001). The highest mortality occurs in the killing front and remaining beech that survive are either highly defective or exhibit resistance (Houston, 1975). The aftermath zone supports lingering populations of beech scale and Neonectria where affected trees can persist in a state of reduced vigor for many years. This disease cycle has parallels in Europe where large beech that survive beech bark disease serve as sources of inoculum for C. fagisuga outbreaks which spread to regenerating or newly planted beech (Shigo, 1972; Houston et al., 1979b). Symptoms of BBD were not observed on native American beech (Fagus grandifolia Ehrh.) until 1920 
(Shigo, 1972). American beech has proven to be extremely susceptible to beech bark disease resulting in mortality that has reached upwards of 30 to 50 percent (Garnas et al., 2011; Kasson and Livingston, 2012). The disease has spread at a predictable rate of 14.7 km/year, reaching Maine, New Hampshire and Massachusetts by 1935 (Wainhouse, 1980; Morin et al., 2007). Disjunct areas of disease distribution, such as the isolated population in Michigan can most likely be attributed to human factors including transport by firewood (Morin et al. 2007).

The disease is initiated by the non-native beech scale, Cryptococcus fagisuga (syn. Cryptococcus fagi Baer.) (Shigo, 1964). First instar C. fagisuga nymphs or crawlers are primarily responsible for the establishment of new populations and are the only instar which is mobile. Once a suitable host beech tree is found, the insects insert their stylets into the cambium to feed and remain for all subsequent instars. C. fagisuga like most scale insects is parthenogenetic and can produce up to 50 young from a single foundress (Wainhouse, 1980; Krabel and Petercord, 2000). First instar nymphs are passively disseminated by wind and will often be in highest concentrations corresponding with predominant wind direction (Houston et al., 1979a; Wainhouse, 1980). Populations are generally restricted to the lower bole (between 1 and $3.2 \mathrm{~m}$ ) and that is where most of the local dispersal occurs between beech trees (Wainhouse, 1980). The most important time period for dispersal is from late summer through fall (July to November) (Wainhouse, 1980). Insects can also be spread by other means including on the feet of birds and by other animals (Houston et al., 1979a). Scale can be transported over longer distances by faster moving wind near the top of the canopy (Wainhouse, 1980). 
A second, generalist scale insect Xylococculus betulae Perg., also attacks beech but has a relatively nominal effect on the overall severity of BBD (Houston et al., 1979a; Wiggins et al., 2004). However this species is instrumental in providing suitable substrate in the form of callused cracks near branch collars for subsequent attack by $C$. fagisuga even though its presence is usually not detected until after C. fagisuga has appeared in a stand (Shigo, 1964). Susceptible beech can survive these infestations but are ultimately weakened and predisposed to Neonectria infection.

The fungal component of the disease complex is comprised of several species of Neonectria (formerly Nectria): Neonectria faginata (M.L. Lohman, A.M.J. Watson \& Ayers) Castl. \& Rossman, Neonectria ditissima (Tul. \& C. Tul.) Samuels \& Rossman and Bionectria ochroleuca (Schwein.) Schroers \& Samuels (Castlebury et al., 2006). N. faginata (syn. Nectria coccinea var. faginata M.L. Lohman, A.M.J. Watson \& Ayers) is the most virulent of the three and is dominant pathogen in the disease complex in North America found exclusively on American beech (Houston, 1994b; Mahoney et al., 1999; Kasson and Livingston, 2009). N. ditissima (syn. Nectria galligena Bres.) is a general pathogen of hardwoods including red maple (Acer rubrum L.), striped maple (A. pennsylvanicum L.), yellow birch (Betula alleghaniensis Britt.) and sugar maple (A. saccharum L.) (Brandt, 1964; Houston, 1994b). On other hardwood species, N. ditissima produces perennial 'target' cankers and greatly diminishes the value of the affected tree. Both of these species can co-occur on a single tree and enter through feeding wounds created by the beech scale insect (Shigo, 1972; Kasson and Livingston, 2009). The mechanism of infection by Neonectria has not been completely elucidated. However 
Ehrlich's study suggests that the feeding of the insect causes local cell desiccation around the wound resulting in injury to surrounding cells. The fungus is able to then penetrate into those compromised cells via the resulting cracks in the bark (Ehrlich, 1934; Lonsdale and Sherriff, 1983; Ostrofsky and Blanchard, 1983). Timing of infection appears to be very important and greatest canker development coincides with spore discharge in the fall (Ostrofsky and Blanchard, 1983). Scale feeding wounds are not a necessary precursor to infection and the pathogen is able to penetrate healthy, previously unwounded tissues and produce cankers, but to a limited extent (Ostrofsky and Blanchard, 1983). In heavily infested trees, the cankers in the cambium that result from Neonectria infection can coalesce, girdle and eventually kill the tree.

\section{Beech Natural History}

American beech was historically distributed in the forests of most of the eastern United States. Populations can occur on numerous soil types but grow primarily in mesic to sandy uplands (Barnes and Wagner, 2004). Beech is a dominant species of northern hardwood forests along with A. saccharum, Tsuga canadensis L. and Quercus rubra L.. It is a monoecious species that also reproduces clonally by root sprouts (Jones and Raynal 1986). Vegetative reproduction becomes important for beech following wounds or stress and does not occur until the root callus tissue is compromised (Jones and Raynal, 1986; Burns and Honkala, 1990). After a disturbance resulting from either tree mortality or removal from logging, vegetative reproduction increases rapidly leading to a condition referred to as beech brush (Houston, 1975; Nyland et al., 2006). Dense thickets of clonal beech sprouts are produced and choke out most other shade tolerant species due to its 
higher shade tolerance (Burns and Honkala, 1990; Cale et al., 2013). The result is a monoculture of beech clones that are susceptible to beech bark disease and are likely to be killed when the disease cycle reinitiates (Houston, 1994a).

Beech is a valuable tree for wildlife. It is one of the northerly-most distributed mast-producing tree species along with maple and sporadic oak. Beech nuts are a high quality food source for many species of wildlife ranging from small mammals such as squirrels to black bear and deer and can be vital for reproduction (McLaughlin et al., 1994; Jakubas et al., 2005; Rosemier and Storer, 2010). Seed production occurs after the tree has reached 40 years. A crop is then produced every 4 to 8 years (Burns and Honkala, 1990). Structurally, beech provides habitat as snags for nesting cavities for both birds and mammals such as porcupines (Kahler and Anderson, 2006). Beech is also harvested for timber applications including for flooring, veneer, containers and furniture (Burns and Honkala, 1990). Historically it was neglected during harvests due to its relatively inferior wood which was prone to warping. Modern heat and pressure treatments have reduced the degree of warping and as a result beech has become more valuable (Shigo, 1972; Nguila Inari et al., 2006).

\section{Beech Bark Disease Management and Resistance}

Past management strategies for hardwoods in the United States, including beech, may have contributed to the severity of the disease in the early stages. Selective harvesting of more valuable species including sugar maple left a larger proportion of beech in the northern hardwood forests (Houston, 1975). Additionally, due to this 
selective harvesting, beech trees beyond maturity remained which would be most susceptible to beech bark disease once the disease arrived (Houston, 1994a).

There are several native organisms that feed on C. fagisuga including the twicestabbed ladybird beetle, Chilocorus stigma Say and several species of predatory mites (Mayer and Allen, 1982). While the ladybird beetles are voracious predators of adult scale insects in stands which are heavily infested, they have a minimal effect on overall populations. Additionally several species of mites including Anystis sp., Abrolophus sp. and Leptus sp. feed on the eggs of C. fagisuga but not to a degree which has a negative impact on the disease incidence (Mayer and Allen, 1982; Wiggins et al., 2001). Due to their minimal impact, these species are not a reliable means of biological control in beech bark disease.

Control of scale insects to the degree needed for a noticeable effect in the landscape is not feasible because host beech are often restricted to forests which are not easily accessible. Management strategies would employ silvicultural prescriptions to consider the susceptibility of beech and the temporal stage of the disease and remove highly susceptible and over-mature trees (Heyd, 2005). Conversely, identification and retention of beech which are resistant or tolerant to BBD is paramount (Heyd, 2005).

The disease does not kill all trees that are exposed to it; approximately one to five percent of the population of American beech exhibit resistance (Houston, 1983; Ostrofsky and Blanchard, 1983). Several hypotheses have been proposed to explain the mechanism of resistance or susceptibility. Most studies focus on resistance to $C$. 
fagisuga because it is the primary factor in BBD spread (Houston and Houston, 2000; Krabel and Petercord, 2000; Ramirez et al., 2007; Koch et al., 2010). These studies observed differences in genetics between resistant and susceptible beech, and found that resistance to C. fagisuga may be related to associated production of primary and secondary metabolites.

The production of metabolites may not be completely of endogenous origin. The role of bark-inhabiting fungal endophytes may influence bark chemistry and resistance potential. Ecology of endophytes, organisms living within plant tissues asymptomatically, has not been exhaustively studied in forest trees (Petrini, 1991; Bills, 1995; Vicari, 1997). Fungal endophytes within grasses were studied extensively due to exhibited antagonism of insect pests (Carroll, 1988; Christensen and Latch, 1991). The mutualistic relationship between the plant and endophytes was perpetuated by dissemination of fungal spores within the seeds of the plant. Most endophytes, including those inhabiting forest trees, must become reestablished in host tissues and fungal distribution and diversity can vary on a temporal and environmental gradient (Carroll, 1988; Sahashi et al., 1999). Endophyte assemblages in beech have been studied but mainly in twigs and leaves (Sahashi et al., 1999; Danti et al., 2002). Beech bark disease occurs on the bole of beech trees and therefore species that inhabit cambium tissue in beech could directly influence disease incidence or severity. In the aftermath zone in the United States, fungal endophyte diversity within cambium tissue was analyzed for beech trees affected by BBD (Cotter and Blanchard, 1982; Baird et al., 2007). Sampling technique and locations have varied in previous studies and the effect of disease stage on 
beech mycoflora has not been considered. The endophytic fungi of Michigan's beech after the onset of beech bark disease have not been thoroughly investigated (Cotter and Blanchard, 1982).

The beech bark disease monitoring and impact analysis system (BBDMIAS) was established in Michigan as a cooperative effort between the Michigan Department of Natural Resources (MDNR), Michigan State University and the University of Michigan in 2000. A network of 202 plots, divided equally between Michigan's two peninsulas, was established using Michigan Department of Natural Resources and United States Forest Service (USFS) compartment maps, forest inventory (FIA) data, on federal, state and private land. The goal of the plot measurements was to compare forest health and canopy composition changes throughout the temporal and spatial progression of beech bark disease in Michigan (Petrillo et al., 2004).

By 2009 the advancing front of beech bark disease had expanded to include 14 counties in the Lower Peninsula (Wieferich et al., 2011). The BBDMIAS plots in the Lower Peninsula of Michigan were visited and reevaluated in 2012 to compare changes in forest health and the progression of BBD from initial plot establishment. The identification of beech bark disease and its further progression in Michigan is critical to convey to managers and other stakeholders. Communication of up to date treatment and mitigation options in light of beech bark disease is equally important. Surveys have revealed resistant beech and continuation of efforts to identify and propagate resistant trees is necessary for the perpetuation of beech as a component of northern hardwood forests in Michigan. 
The latest revisitation of the BBDMIAS plots in 2011-2012 are presented in this thesis which focuses on disease progression and changes in canopy condition of BBD affected beech in Michigan and its associated impacts. New investigations of the functions of cambium-inhabiting fungal endophytes and their interactions with Neonectria were explored in vitro as a potential beech bark disease resistance mechanism. 


\section{Literature Cited}

Baird, R.E., Watson, C.E., Woolfolk, S., 2007. Microfungi from bark of healthy and damaged American beech, fraser fir, and eastern hemlock trees during an all taxa biodiversity inventory in forests of the Great Smoky Mountains National Park. Southeastern Naturalist 6, 67-82.

Barnes, B.V., Wagner, W.H., 2004. Michigan Trees: A Guide to the Trees of the Great Lakes Region. The University of Michigan Press, Ann Arbor, Michigan.

Bills, G.F., 1995. Analysis of microfungal diversity from a user's perspective. Canadian Journal of Botany 73, S33-S41.

Brandt, R.W., 1964. Nectria canker on hardwoods. In: Agriculture, U.S.D.o. (Ed.). Northeastern Forest Experiment Station, New Haven, CT, pp. 1-7.

Burns, R.M., Honkala, B.H., 1990. Silvics of North America: 2, Hardwoods. U.S. Department of Agriculture, Forest Service, Washington, DC.

Cale, J.A., McNulty, S.A., Teale, S.A., Castello, J.D., 2013. The impact of beech thickets on biodiversity. Biological Invasions 15, 699-706.

Carroll, G., 1988. Endophytes in stems and leaves: From latent pathogen to mutualistic symbiont. Ecology 69, 2-9.

Castlebury, L.A., Rossman, A.Y., Hyten, A.S., 2006. Phylogenetic relationships of Neonectria/Cylindrocarpon on Fagus in North America. Canadian Journal of Botany 84, 1417-1433. 
Christensen, M.J., Latch, G.C.M., 1991. Variation among isolates of Acremonium endophytes (A. coenophialum and possibly A. typhinum) from tall fescue (Festuca arundinacea). Mycological Research 95, 1123-1126.

Cotter, H.V., Blanchard, R.O., 1982. The fungal flora of bark of Fagus grandifolia. Mycologia 74, 836-843.

Danti, R., Sieber, T.N., Sanguineti, G., 2002. Endophytic mycobiota in bark of European beech (Fagus sylvatica) in the Apennines. Mycological Research 106, 1343-1348.

Ehrlich, J., 1934. The beech bark disease: A Nectria disease of Fagus, following Cryptococcus fagi (Baer.). Canadian Journal of Research 10, 593-692.

Garnas, J.R., Ayres, M.P., Liebhold, A.M., Evans, C., 2011. Subcontinental impacts of an invasive tree disease on forest structure and dynamics. Journal of Ecology 99, $532-541$.

Gwiazdowski, R.A., Van Driesche, R.G., Desnoyers, A., Lyon, S., Wu, S.-a., Kamata, N., Normark, B.B., 2006. Possible geographic origin of beech scale, Cryptococcus fagisuga (Hemiptera: Eriococcidae), an invasive pest in North America. Biological Control 39, 9-18.

Heyd, R.L., 2005. Managing beech bark disease in Michigan. In: Evans, C.A., Lucas, J.A., Twery, M.J. (Eds.), Beech Bark Disease: Proceedings of the Beech Bark Disease Symposium, Saranac Lake, New York, pp. 128-132.

Houston, D.B., Houston, D.R., 2000. Allozyme genetic diversity among Fagus grandifolia trees resistant or susceptible to beech bark disease in natural populations. Canadian Journal of Forest Research 30, 778-789. 
Houston, D.R., 1975. Beech Bark Disease: The Aftermath Forests are Structured for a New Outbreak. Journal of Forestry 73, 660-663.

Houston, D.R., 1983. American beech resistance to Cryptococcus fagisuga. In, I.U.F.R.O. Beech Bark Disease Working Party Conference. USDA Forest Service, Northeastern Forest Experiment Station. Gen. Tech. Rep. WO-37., Hamden, CT.

Houston, D.R., 1994a. Major new tree disease epidemics: Beech bark disease. Annual Review of Phytopathology 32, 75-87.

Houston, D.R., 1994b. Temporal and spatial shift within the Nectria pathogen complex associated with beech bark disease of Fagus grandifolia. Canadian Journal of Forest Research 24, 960-968.

Houston, D.R., Parker, E.J., Lonsdale, D., 1979a. Beech bark disease: Patterns of spread and development of the initiating agent Cryptococcus fagisuga. Canadian Journal of Forest Research 9, 336-344.

Houston, D.R., Parker, E.J., Perrin, R., Lang, K.J., 1979b. Beech bark disease: A comparison of the disease in North America, Great Britain, France and Germany European Journal of Forest Pathology 9, 199-211.

Jakubas, W.J., McLaughlin, C.R., Jensen, P.G., McNulty, S.A., 2005. Alternate year beechnut production and its influence on bear and marten populations. In: Evans, C.A., Lucas, J.A., Twery, M.J. (Eds.), Proceedings of the Beech Bark Disease Symposium. US. Department of Agriculture, Forest Service, Northeastern Research Station, Saranac Lake, New York, pp. 79-87. 
Jones, R.H., Raynal, D.J., 1986. Spatial distribution and development of root sprouts in Fagus grandifolia (Fagaceae). American Journal of Botany 73, 1723-1731.

Kahler, H.A., Anderson, J.T., 2006. Tree cavity resources for dependent cavity-using wildlife in West Virginia forests. Northern Journal of Applied Forestry 23, 114121.

Kasson, M.T., Livingston, W.H., 2009. Spatial distribution of Neonectria species associated with beech bark disease in northern Maine. Mycologia 101, 190-195.

Kasson, M.T., Livingston, W.H., 2012. Relationships among beech bark disease, climate, radial growth response and mortality of American beech in northern Maine, USA. Forest Pathology 42, 199-212.

Koch, J.L., Carey, D.W., Mason, M.E., Nelson, C.D., 2010. Assessment of beech scale resistance in full- and half-sibling American beech families. Canadian Journal of Forest Research 40, 265-272.

Krabel, D., Petercord, R., 2000. Genetic diversity and bark physiology of the European beech (Fagus sylvatica): A coevolutionary relationship with the beech scale (Cryptococcus fagisuga). Tree Physiology 20, 485-491.

Lonsdale, D., Sherriff, C., 1983. Some aspects of the ecology of Nectria on beech. In, I.U.F.R.O. Beech Bark Disease Working Party Conference. USDA Forest Service, Northeastern Forest Experiment Station., Hamden, CT, pp. 59-68.

Mahoney, E.M., Milgroom, M.G., Sinclair, W.A., Houston, D.R., 1999. Origin, genetic diversity and population structure of Nectria coccinea var. faginata in North America. Mycologia 91, 583-592. 
Mayer, M., Allen, D.C., 1982. Chilocorus stigma (Coleoptera: Coccinellidae) and other predators of beech scale in central New York. In, IUFRO Beech Bark Disease Working Party Conference, Hamden, CT, pp. 89-98.

McCullough, D.G., Heyd, R.L., O'Brien, J.G., 2001. Biology and management of beech bark disease: Michigan's newest exotic forest pest. In. Michigan State University Extension.

McLaughlin, C.R., Matula, G.J., Jr., O'Connor, R.J., 1994. Synchronous Reproduction by Maine Black Bears. Bears: Their Biology and Management 9, 471-479.

Morin, R.S., Liebhold, A.M., Tobin, P.C., Gottschalk, K.W., Luzader, E., 2007. Spread of beech bark disease in the eastern United States and its relationship to regional forest composition. Canadian Journal of Forest Research 37, 726-736.

Nguila Inari, G., Petrissans, M., Gerardin, P., 2006. Chemical reactivity of heat-treated wood. Wood Science and Technology 41, 157-168.

Nyland, R.D., Bashant, A.L., Bohn, K.K., Verostek, J.M., 2006. Interference to Hardwood Regeneration in Northeastern North America: Ecological Characteristics of American Beech, Striped Maple, and Hobblebush. Northern Journal of Applied Forestry 23, 53-61.

Ostrofsky, W.D., Blanchard, R.O., 1983. Characteristics and development of necrophylactic periderms in mature bark of American beech. In, I.U.F.R.O. Beech Bark Disease Working Party Conference. USDA Forest Service, Northeastern Forest Experiment Station, Hamden, CT. 
Petrillo, H.A., Witter, J.A., Thompson, E.M., 2004. Michigan beech bark disease monitoring and impact anlaysis system. In, Beech Bark Disease Symposium, Saranac Lake, NY, pp. 48-51.

Petrini, O., 1991. Fungal Endophytes of Tree Leaves. In: Andrews, J.H., Hirano, S.S. (Eds.), Microbial Ecology of Leaves. Springer New York, pp. 179-197.

Ramirez, M., Loo, J., Krasowski, M.J., 2007. Evaluation of resistance to the beech scale insect (Cryptococcus fagisuga) and propagation of American beech (Fagus grandifolia) by grafting. Silvae Genetica 56, 163-169.

Rosemier, J.N., Storer, A.J., 2010. Assessing the responses of native small mammals to an incipient invasion of beech bark disease through changes in seed production of American beech (Fagus grandifolia). The American Midland Naturalist 164, 238259.

Sahashi, N., Kubono, T., Miyasawa, Y., Ito, S., 1999. Temporal variations in isolation frequency of endophytic fungi of Japanese beech. Canadian Journal of Botany 77, 197-202.

Shigo, A.L., 1964. Organism interactions in the beech bark disease. Phytopathology 54, 263-269.

Shigo, A.L., 1972. The beech bark disease today in the northeastern U.S . Journal of Forestry 70, 286-289.

Vicari, M. (Ed.), 1997. Endophytic Fungi in Grasses and Woody Plants. APS Press St Paul, Minnesota.

Wainhouse, D., 1980. Dispersal of first instar larvae of the felted beech scale Cryptococcus fagisuga. Journal of Applied Ecology 17, 523-532. 
Wieferich, D.J., McCullough, D.G., Hayes, D.B., Schwalm, N.J., 2011. Distribution of American beech (Fagus grandifolia) and beech scale (Cryptococcus fagisuga Lind.) in Michigan from 2005 to 2009. Northern Journal of Applied Forestry 28, 173-179.

Wiggins, G.J., Grant, J.F., Eelbourn, W.C., 2001. Allothrombium mitchelli (Acari: Trombidiidae) in the Great Smoky Mountains National Park: Incidence, seasonality and predation on beech scale (Homoptera: Eriococcidae). Ecology and Population Biology 94, 896-901.

Wiggins, G.J., Grant, J.F., Windham, M.T., Vance, R.A., Rutherford, B., Klein, R., Johnson, K., Taylor, G., 2004. Associations between causal agents of the beech bark disease complex [Cryptococcus fagisuga (Homoptera: Cryptococcidae) and Nectria spp.] in the Great Smoky Mountains National Park. Environmental Entomology 33, 1274-1281. 


\title{
Chapter 2:
}

\section{Beech bark disease distribution and development in Michigan's Lower Peninsula. $^{1}$}

\begin{abstract}
Beech bark disease (BBD) is a non-native association between a scale insect (Cryptococcus fagisuga) and one or more pathogenic ascomycetes in the genus Neonectria resulting in rapid and widespread mortality of American beech (Fagus grandifolia) in North America. To observe the effects of BBD, forest health indicators and composition metrics such as basal area, were collected in 202 monitoring plots established in Michigan following disease discovery in 2000 and were most recently revisited in 2011-2012. Survey data indicated that BBD had reduced overall health of affected beech in 2012 based on significant increases in vigor rating and dead beech basal area compared to plot establishment. C. fagisuga was found in each of the 22 counties in Michigan's Lower Peninsula which contained monitoring plots and exhibited significant spatial clustering. Neonectria was found in Emmet, Cheboygan and Wexford counties in the Lower Peninsula which may coincide with additional BBD introduction locations. Surveys for BBD resistance resulted in five apparently resistant beech which were added to a BBD resistance database. The initial introduction site of BBD in Ludington State Park has progressed to an aftermath forest based on observations of highly defective trees and relatively reduced scale populations compared to surrounding areas.
\end{abstract}

\footnotetext{
${ }^{1}$ The material contained in this chapter is in preparation for journal submission.
} 


\section{Introduction}

Beech bark disease is an association between a non-native beech scale insect (Cryptococcus fagisuga Lind.) and one or more pathogenic ascomycetes in the genus Neonectria (Ehrlich, 1934; Shigo, 1964). The disease has been spreading throughout the range of American beech (Fagus grandifolia Ehrh.) since its introduction to North America in the 1890s (Ehrlich, 1934). The scale insect is responsible for dissemination of the disease and is transported by wind, animals or by humans on firewood (Houston et al., 1979; Wainhouse, 1980). Pioneer populations of C. fagisuga become established on host beech along the leading edge or the advancing front. Subsequent stages are reached once the pathogenic fungus, either Neonectria faginata or Neonectria ditissima join the scale insect. The second stage of beech bark disease induced is described as the killing front. Populations of Neonectria and C. fagisuga are high and rampant canker formation causes widespread mortality in this stage. The final stage represents a crash in the population of beech, which still harbors a residual population of beech scale and Neonectria (Shigo, 1964).

American beech (Fagus grandifolia) is extremely susceptible to the disease and most trees that are able to fend off attack during the first killing front are defective and susceptible to windthrow or beech snap (Papaik et al., 2005). The production of clonal root suckers after stress, such as that caused by beech bark disease, has led to some aftermath forests regenerating as a dense monoculture of beech (Houston, 1975). However, one to five percent of the population exhibit resistance in all stages and are able to survive the combination of insect and pathogen. Due to the prolific and easily 
dispersed beech scale, control measures are impractical. Therefore resistance should be the focus of management strategies to promote the long-term survival of American beech. The mechanisms of resistance have been investigated and implicate the production of certain primary and secondary metabolites and genetics (Dübeler et al., 1997; Houston and Houston, 2000; Krabel and Petercord, 2000; Koch et al., 2010). In addition, the integrity and structure of bark may act as a barrier to insect colonization (Morris et al., 2002).

Beech bark disease was discovered in Michigan in both the lower and upper peninsulas in 2000 (O'Brien et al., 2001). Shortly after, the beech bark disease monitoring and impact analysis system (BBDMIAS) was established as a cooperative effort between the Michigan Department of Natural Resources (MDNR), Michigan State University and the University of Michigan. To observe the spread of BBD and its impact on forests, a network of 202 plots, divided equally between Michigan's two peninsulas was established using Michigan Department of Natural Resources (MDNR) and United States Forest Service (USFS) compartment maps, forest inventory (FIA) data on both public private lands. The goal of these plots was to be able compare forest health and canopy composition changes throughout the temporal and spatial progression of beech bark disease in Michigan (Petrillo et al., 2004).

This study is a continuation of the canopy condition measurements collected from those plots within the Lower Peninsula. Our hypotheses were that the forest health assessments in 2011-2012 would show declines in forest health from initial observations in 2001, and that areas with high incidence of disease would include trees that appear to 
be resistant to the disease complex. The objectives were to i) map the extent of beech bark disease in Michigan using the protocols established from the BBDMIAS and to ii) characterize the progression of beech bark disease and tree decline since disease discovery in 2000 and to iii) identify resistant beech trees in areas with heavy beech scale (Cryptococcus fagisuga).

\section{Materials and Methods}

\section{Study Area}

Beech bark disease monitoring and impact analysis (BBDMIAS) plots were located in 22 counties in Michigan's Lower Peninsula (L.P.) mostly in the western portion of the state coinciding with suitable beech habitat. Plots were located within national forest (32 plots), national lakeshore (7), state forest (43), state parks (14) and on private lands (1) (Figure 2.1). Descriptions of BBDMIAS plot descriptions are reported briefly here and are described in detail in the original protocol (Petrillo et al., 2004). Plots consisted of 30 marked and numbered beech trees in a five by six or three by ten transect matrix. Prism points were spaced at regular 40 meter intervals along each parallel transect per plot and were associated with one numbered sample beech tree. Prism points were natural features (trees or shrubs) marked with flagging or paint within the plot. The nearest beech to the prism point that was alive and over $10 \mathrm{~cm}$ DBH was selected as the sample beech. A numbered tag was hammered into a buttressed root of the sample beech which indicated the rough direction to the prism point. Azimuth and distance from the sample beech to the prism point were also recorded for relocation in subsequent years. 
Sample beech trees that were not relocated in 2011-2012 may have been harvested or their identifying features (tags, flagging) removed. These missing or harvested beech were not replaced in the plot. However the establishment of new prism point trees was necessary when previously marked prism point trees could not be found for a relocated sample beech tree. New prism points were selected based on the following hierarchical protocol: 1) If the sample beech was counted when observed through a 10 factor basal area prism from the new prism point; 2) if the new prism point was not the same individual as the sample beech; 3 ) if the new prism tree was alive and in good health; 4) if the new prism points coincided with approximately the same compass direction as the tag and/or blue dot on the sample beech; and 5) the new prism point was not be closer to another beech greater than $10 \mathrm{~cm}$ DBH other than the sample beech. The approximate sizes of these plots ranged from 2.9 to 3.2 hectares.

\section{Field Survey of Beech}

To aid in initial location of the plot, witness trees were established and labeled with a large, blue dot close to roadways or paths leading to the plot. GPS location, species, and azimuth to the first sample beech tree in the plot were entered for each witness tree. Within the plot, each of 30 beech trees that were located were tagged with a small, numbered, aluminum tag and marked with blue paint and orange flagging tape. During the 2011 visits, the locations of all marked beech trees found were recorded using a Garmin GPSMap ${ }^{\circledR} 76$ or 78 GPS unit (Garmin International Inc., Olathe, KS). Basal area of all species was recorded at the associated prism points for each of the 30 beech 
trees per plot. Measurements included both dead and live beech using a ten factor wedge prism (Petrillo et al., 2004).

Forest health canopy assessments, developed by the USFS were conducted for each tree in the plot (Schomaker et al., 2007). To create an overall image of the tree in terms of health estimates were made of uncompacted live crown ratio (ULCR), percent dieback, crown light exposure, crown class, crown density and foliage transparency (Schomaker et al., 2007). These measurements are briefly described below. Uncompacted live crown ratio represents the percent of the vertical height of the tree which had continuous foliage. Percent dieback of the canopy is recorded as the proportion of recently dead branches extending from the top and sides of the tree inward. Foliage transparency is the amount of light that passes through gaps in the leaves compared to a standard image where the proportion of light and dark colored pixels correspond to sunlight and leaves respectively. A lower value indicated a less transparent, healthier canopy. Canopy density measures the amount of light that passes through the canopy including foliage, branches and other structures such as seeds. The missing proportion of the canopy is deduced by visualizing a symmetrical tree crown and subtracting the missing percentage; this adjustment represented the density of the entire symmetrical crown. Uncompacted live crown ratio, percent dieback, foliage transparency and canopy density are each classified in five percent categories from 0 to 100.

Crown light exposure was recorded as the amount of light a tree receives in terms of the number of sides of that tree which would be exposed to light at noon. A normal 
co-dominant tree would receive 1-2 sides of light where an understory tree would receive zero. Crown class represented the tree's position within the canopy as a ranking from one to five. A co-dominant tree would be ranked as three where a suppressed or overtopped tree would be ranked as five. Tree vigor was a classification of tree health ranging from 1 to 12 in which higher values corresponded to decreasing health (Schomaker et al., 2007). Incidence of the 15 different types of secondary damages ranging from cankers and galls to discolored foliage which had the greatest effect on a tree's condition were also recorded. Measurements were conducted independently by two observers separated by approximately 90 degrees. Conclusions by each person were compared and an agreed upon number between both was recorded to reduce bias. To measure radial growth, diameter at breast height (DBH) was recorded for each sample beech.

To quantify beech bark disease severity, visual estimates of beech scale $(C$. fagisuga) density were recorded at cardinal directions on each sample tree using a 12.5 cm by $28 \mathrm{~cm}$ transparency frame at 1.5-2m height (Petrillo et al., 2004). Percent cover of the bark by scale insects was assigned to five percent intervals from 0 to 99 percent. Trees that supported a very low population where visible scale was less than five percent were arbitrarily assigned as one percent cover.

Neonectria influence was estimated by presence of tarry spots. These were dark, oozing areas of necrotic tissue thought to be associated with Neonectria cankers. Presence of Neonectria was confirmed if there were perithecia (fruiting structures) on the bole of the tree. 
Resistant trees were defined as having very low to no occurrence of beech scale (C. fagisuga) within beech populations that were heavily infested with scale. These trees were not necessarily associated with the established plots and were marked with a large " $\mathrm{R}$ " in white paint and the location was recorded with a GPS unit. The locations of resistant beech were shared with the Michigan DNR to add to the database of BBD resistance and to be subsequently visited and verified.

\section{Data Analysis}

Only the plots that were visited on each of the four instances of data collection (2001, 2004, 2007 and 2012) were used for analysis. These data represented a continuous measurement from time zero and comprised 56.4\% of plots surveyed in 2012 and $43.1 \%$ of total plots surveyed. Basal area analyses omitted any data from 2007 due to inconsistent collection.

A repeated measures one-way ANOVA was utilized to measure the differences between successive years crown condition variables and basal area data. This test was employed to compensate for the introduced dependency of using the same plot locations over time. Post-hoc multiple comparisons between years was further analyzed using the Fisher's protected paired t-test applying the Bonferroni adjustment to reduce type I error (Zar, 2010). DBH was analyzed using a one-way ANOVA followed by Tukey's HSD test (Zar, 2010). SPSS was used for all ANOVA analyses (SPSS Inc. Released 2008. SPSS Statistics for Windows, Version 17.0. Chicago: SPSS Inc.). 
Spatial analyses of mortality, scale density and Neonectria presence were performed to monitor how beech bark disease has progressed in the BBDMIAS monitoring plots from 2001 to 2012 . These variables were tested to observe for patterns of spatial autocorrelation or clustering defined by the global Moran's index (Austin, 2002; Chang, 2012). This index identified clusters as spatially related groups of high values or dispersion as low values which exhibited a regular non-grouping pattern. The GPS coordinates of the prism trees were associated with data values of C. fagisuga cardinal density measurements and analyzed independently for spatial autocorrelation using ArcMap 10.1 (ESRI, 2012). Each year was successively tested to determine whether the data were becoming more clustered over time.

Spatial interpolation by inverse distance weighting (IDW) was used to map the spatial progression of beech scale by creating a continuous surface from the averaged $C$. fagisuga density measurements from 2001 to 2012 throughout Lower Michigan. The number of neighbors selected was 5-15 for 2001 and 5-30 in 2012.

To determine whether $C$. fagisuga had any effect on other canopy health indicators, north, east, south and west density measurements were independently compared with dieback using several spatial regression calculations. The physical change of landscape elevation or slope values were also considered as a causative variable. These values were interpolated using the nearest neighbor method in ArcMap 10.1 for each sample beech using a $10 \mathrm{~m}$ digital elevation model downloaded from the USGS national map viewer (USGS National Map Viewer http://viewer.nationalmap.gov). Exploratory regression was used to determine initial relationships of the tested variables 
with the dependent variable (percent dieback) and subsequently determined an appropriate ordinary least squares (OLS) model using ArcMap 10.1 (ESRI). Ordinary least squares regression was employed to observe further relationships using an iterative coefficient calculation to predict the change between the dependent variable and each potential causative variable tested.

The global Moran's I calculation was used to test for clustering in basal area and dieback. Basal area was categorized into beech and non-beech and clustering was analyzed on live, dead and total basal area measurements. All spatial statistical analyses were performed using ESRI ArcGIS version 10.1 (ESRI, 2012).

\section{Results}

\section{Beech Bark Disease and Canopy Condition}

Beech bark disease as quantified by C. fagisuga presence was observed in each of the monitoring plots in 2012 except one (Figure 2.2). Neonectria faginata was first found in the BBDMIAS plots in the Lower Peninsula in 2011-2012. However populations were sparse and perithecia were only observed on ten trees within seven different plots in Cheboygan, Emmet and Wexford counties. However, 11\% $(\mathrm{n}=234)$ of sample beech exhibited tarry spots, another sign of $N$. faginata infection. Five new resistant beech were identified in 2011 and remained without scale in 2012 in Luce, Mason and Emmet counties. Fifteen additional potential resistant trees were located in 2011 in areas with relatively high scale densities which were not revisited. 
In 2012 the most frequently observed damages were advanced decay or Basidiomycete fruiting structures (20.2\%), cracks and seams (6.7\%), followed by cankers or galls (5.0\%), open wounds (4.5\%) and broken or dead branches (2.8\%) (Table 2.1).

The proportion of mortality in the sample beech tree averaged 5.2\% in 2012 which was an increase from $2.4 \%$ in 2004 . This coincides with a significant reduction in live and total beech basal area and a significant increase in dead beech basal area from $2001(\mathrm{p}<0.001)$ (Figure 2.3). Live non-beech basal area has also shown a significant decline from $2004(\mathrm{p}=0.009)$ but was not significantly different than $2001(\mathrm{p}=0.830)$ (Figure 2.4).

Mean percent dieback has shown a decreasing trend over time from $3.4 \pm 0.09$ percent (mean \pm standard error) in 2001 to $2.5 \pm 0.14$ in 2012. 2012 data was significantly lower than 2001 and $2004(\mathrm{p}<0.001) .2004$ and 2007 also showed a highly significant decline in dieback $(\mathrm{p}<0.001)$ (Figure 2.5).

Differences in crown density were significant between years $(\mathrm{p}<0.001)$ (Figure 2.6). Individual years varied in differences as 2012 showed a significant decline from $2007(\mathrm{p}<0.001)$ but was still a significant increase from $2004(\mathrm{p}<0.001)$ (designated by different lower case letters in Figure 2.4). Percent crown ratio was significantly different each year $(\mathrm{p}<0.001)$ with an exception of from 2001-2004 ( $\mathrm{p}=0.235)$ (Figure 2.6).

Diameter at breast height (DBH) increased at a gradual rate throughout the years (Figure 2.7). However, none of the years were significantly different than any others. 
Foliage transparency indicated a pairwise relationship of significant decline and subsequent rebound between 2001 and $2004(17.5 \pm 0.25$ to $29.2 \pm 0.21)$ and 2007 to $2012(20.9 \pm 0.30$ to $25.9 \pm 0.26)$ showing an overall increase in transparency over time $(\mathrm{p}<0.001)$ (Figure 2.8).

Differences in vigor between each pair of years, 2001-2004, 2001-2007 etc. were significant and the overall trend was increased vigor rating over time (Figure 2.9). The increased values reflect a decline in tree health.

\section{Spatial Analysis}

Percent cover of scale insects in each cardinal direction (north, east, south and west) of data collected in 2001 to 2003 clustered significantly ( $<<0.01$ for all directions). The associated Moran's index values ranged from 0.335 to 0.351 in 2001 . Each subsequent year of data collection including 2004, 2007 and 2012 also showed significant clustering in each cardinal direction of scale density ( $p<0.01)$. In 2012 global Moran's indices did not increase from 2001 values (range of 0.243 to 0.301 ) which indicate that $C$. fagisuga is not becoming increasingly clustered over time.

Percent dieback, which is associated with tree stress also showed significant clustering in all four years $(\mathrm{p}<0.01)$. Moran's index values, with the exception of 2001 (0.075) showed an increasing trend, ranging from 0.0574 (2004) to 0.1229 (2012). Dieback according to the Moran's indices is becoming more clustered over time.

Exploratory regression revealed that the west scale density had a negative relationship with dieback and east had the strongest positive relationship in 2001 
$\left(\mathrm{R}^{2}=0.02\right)$ (Table 2.2). In 2004, north, west and east scale densities had a significant $(\mathrm{p}<0.01)$ positive relationship with dieback: west $\left(\mathrm{R}^{2}=0.04\right)$, north $\left(\mathrm{R}^{2}=0.03\right)$ and east $\left(\mathrm{R}^{2}=0.03\right)$. A positive north scale density relationship with dieback also observed in 2007 $\left(\mathrm{p}<0.05, \mathrm{R}^{2}=0.05\right)$. The exploratory regression in 2012 also revealed that the north scale density had the strongest relationship with dieback $\left(\mathrm{p}=0.05, \mathrm{R}^{2}=0.05\right)$ followed by east scale density but the relationship was not strong $\left(\mathrm{p}=0.01, \mathrm{R}^{2}=0.01\right)$.

Ordinary least squares regression revealed a similar positive relationship between the east scale density and dieback in $2001(\mathrm{p}<0.001)$. Additionally OLS regression showed a significant negative relationship with dieback and north scale readings $(\mathrm{p}=0.008)$. In 2007 , the highly significant relationship of north scale density and dieback was confirmed in OLS regression $(\mathrm{p}<0.001)$. Additionally slope was identified as having a negative relationship with dieback $(\mathrm{p}=0.019)$. Ordinary least squares regression further showed that both the east aspect scale density and slope had significant ( $\mathrm{p}=0.010$ and $\mathrm{p}<0.001$ respectively) relationships to dieback in 2012 .

Inverse distance weighting (IDW) interpolation revealed a spatial change in $C$. fagisuga distribution in the decade that the insect has been monitored (Figure 2.10). In 2001-2003, the insect's populations were restricted to locations surrounding the initial introduction point in Lower Michigan. 2012 showed a radial progression of higher scale density encompassing the original point of introduction. Additionally, two separate introduction points are revealed in Wexford county northeast of the initial disease introduction location and in Emmet county in the northwest tip of the Lower Peninsula. 
Beech basal area was significantly clustered up until 2012. All beech (live, dead and total) basal area in 2001 was significantly clustered $(p<0.001)$ and the same clustered pattern was observed in 2004 and $2007(\mathrm{p}<0.001)$. In 2012 both live and dead beech basal area was significantly dispersed $(\mathrm{p}<0.001)$. Total beech however was randomly distributed $(\mathrm{p}=0.846)$. Both dead and still living beech are becoming less clustered over time illustrated by decreasing Moran's index values from 0.218 in 2001 to -0.163 in 2012 for dead and 0.235 (2001) to -0.142 (2012) for live beech.

Live and total non-beech basal area was significantly dispersed in $2001(\mathrm{p}=0.043$ and $\mathrm{p}=0.044$ respectively). Dead non-beech in 2001 was randomly distributed $(\mathrm{p}=0.369)$. Dead, live and total non-beech basal area were randomly distributed in 2004 ( $\mathrm{p}=0.473$, $\mathrm{p}=0.147$ and $\mathrm{p}=0.122$ respectively). 2007 also showed a significantly dispersed distribution of live and total non-beech basal area ( $\mathrm{p}=0.013$ and 0.006 respectively). Non-beech live basal area in 2012 was significantly clustered $(\mathrm{p}<0.001)$. Overall live non-beech species are becoming increasingly clustered over time with Moran's index values of -0.0162 in 2001 and 0.0721 in 2012 .

\section{Discussion}

\section{BBDMIAS Canopy Condition}

The impacts of BBD were apparent when considered in relation to the canopy conditions that were assessed on live beech within the BBDMIAS plots. Overall beech mortality increased and corresponded with a decrease in live and overall beech basal area. A similar pattern of overall decline in basal area was observed in non-beech species. 
This indicates that beech are dying before the surrounding tree species can respond to the openings in the canopy. The degree of dense beech sucker formation or beech brush may have contributed to the lack of regeneration in other species (Cale et al., 2013). Even though beech have declined, the values of beech mortality may be artificially low for several reasons. In many of the state park plots, the full assessment of sample trees could not be completed due to missing or vandalized tags. Particularly in Ludington state park, where the disease was suspected to have begun in Michigan, many trees in the location where sample beech should have been were dead and down and had no identification to help link them to the plot. Therefore the results from Ludington may have had an artificially low mortality value. This phenomenon was also observed in other state parks such as P.J. Hoffmaster and Warren Dunes. However the remaining trees in these locations contributed valuable live basal area information.

Vigor rating showed an increasing trend over time indicating either trees are becoming increasingly affected by the disease or are less healthy. This coincides with the abrupt increase in sample beech mortality to $5.2 \%$ in 2012 .

The gradual increase in diameter $(\mathrm{DBH})$ of sample beech over time indicates that beech bark disease is not yet affecting radial growth (Figure 2.7) This is consistent with observations that overall, Michigan is still part of the newer stages of the disease. In the killing front and aftermath zones, DBH decreases markedly over time (Gavin and Peart, 1993; Leak, 2006; Garnas et al., 2011). 
Uncompacted live crown ratio showed an overall decrease over time from 2001 to 2012. This is likely due to normal aging of the forest. The subsequent increase in DBH shows that prism point beech are growing radially and live crown ratio suggests they were also growing vertically, but specific height measurements were not recorded. A loss of lower branches due to shade and self-pruning that correspond with the maturation of the stand could also influence the decrease in crown ratio (Schomaker et al., 2007). The inconsistent pattern from year to year may indicate logging activity which would open up gaps in the canopy and promote epicormic branching, especially from 2007 to 2012 (Burns and Honkala, 1990). Since the creation of the beech bark disease monitoring and impact analysis plots, a ten year rotation period for harvesting had passed. In 2012 a proportion of the sample beech were either marked for harvest or had been harvested in the past two to five years. The decrease in live crown ratio might indicate that beech bark disease is having little effect on the proportion of canopy on any particular beech.

Crown density increased over time, with the exception of 2007 to 2012. The increase shows that the beech crowns are becoming denser over time. This along with the factors contributing to UCLR decline may indicate that lower branches may have an increasing impact. These lower shade leaves tend to be larger and may skew the density measurement higher. Additionally the high crown density anomaly from 2007 to 2012 potentially reflects an inconsistency in data collection. Crown density and foliage transparency are some of those most difficult metrics to accurately measure. The abrupt increase in 2007 may also be a response to localized mortality which would open up areas of the canopy and increase leaf area (Schomaker et al., 2007). 
Initial increases in foliage transparency from 2001 to 2004 correspond with the influence of beech bark disease in thinning and stressing beech canopies. In 2007 an abrupt drop in dieback synchronized with a reduction in foliage transparency indicated a recovery of crown condition. In 2012 the impact of BBD again appeared to stress the canopies and resulted in increased transparency along with a decrease in crown density.

Despite the abundance of scale and associated mortality in some plots, there was a marked lack of Neonectria perithecia. Based on this visual assessment, no confirmation of the pathogen could be made. However, according to Shigo (1972), Neonectria can exist while scale insects are still present and feeding on the phloem. As a result trees can succumb to the disease before favorable conditions arise for sexual reproduction of the pathogen. This phenomenon is suspected in several locations, namely Silver Lake State Park. Beech mortality within these plots within the park averaged 6\% in 2012 yet no Neonectria perithecia were observed.

\section{Spatial Analysis}

Since C. fagisuga is parthenogenetic and immobile in later instars, one would expect the population to be concentrated or clustered. Indeed the distribution of scale populations was largely clustered based the Moran's index calculations of spatial autocorrelation. Studies in aftermath forests found no clustering of scale, perhaps because propagule loads in these forests are not limited (Garnas et al., 2012). In Michigan the disease has been present approximately 20 years and many areas of the state are not yet affected by the later stages of BBD. The localization or clustering of 
populations also may indicate several introduction sites. The severity of BBD in the Lower Peninsula compared to the Upper Peninsula may be explained by the spatial aggregation of beech scale and topographic differences which would limit spread (D. McCullough, pers. comm.).

The interpolation map from 2001-2003 confirmed that Ludington State Park and the areas immediately surrounding it had the highest beech scale density and was consistent with reports that this region was the first introduction point in the Lower Peninsula (O'Brien et al., 2001). The 2012 inverse distance weighting (IDW) analysis revealed Wexford and Emmet Counties to be two additional epicenters which had average scale densities up to $45 \%$, higher than most other areas. Neonectria presence was recorded in both of these counties as well as areas of beech mortality that coincided with observations of $N$. faginata fruiting structures. These results suggest that the area around Ludington has progressed to the aftermath zone indicated by relatively low scale density in 2012 compared to 2001 and high localized mortality. The two new epicenters or introduction points have progressed or may soon transition from the advancing front to the killing front due to $N$. faginata presence and associated mortality.

Dieback was also significantly clustered with increased clustering over time in each successive year of data collection as shown by global Moran's I calculations. The results of the regression analyses in 2012 showed $C$. fagisuga had a significant relationship with dieback. However, the low $\mathrm{R}^{2}$ values indicated that the regression analyses served as poor models of the variables tested. Any positive relationships which would indicate that scale density in a particular direction had a significant relationship 
with dieback were not consistently observed throughout the years (Table 2.2). Overall, significant relationships existed but were not necessarily predictive of one another.

Basal area in 2012 represented an anomaly in an otherwise predictable pattern of beech clustering over time. This may be explained by a discrepancy in the number of trees surveyed each year. While every effort was made to find and record data for each of the 30 trees within the sampling plots, some were not found and those data were missing. Additionally the marked prism points were not always able to be found. More often than not, new prism points were created and this may reflect the difference in basal area distribution. The decreasing Moran's index values of dead and live beech may indicate an effect of beech bark disease on northern hardwood forest composition. Conversely all other species are becoming increasingly clustered over time and may be filling in gaps created by BBD-killed beech.

The apparently resistant beech that were observed can only be confirmed with challenge studies or repeated observation (Koch et al., 2010). Resistant beech were determined based on a lack of C. fagisuga in areas which otherwise were heavily infested. Thus whether the 15 additional identified trees are truly resistant can only be confirmed with time. Several trees which were originally marked as resistant, upon visiting a second year were determined to support scale populations.

Overall, BBD is widespread in Michigan and coincides with the densest areas of beech distribution in the state. Scale is geographically clustered in the Lower Peninsula which may explain the variation in disease severity in the upper and lower peninsulas of 
Michigan. Significant decreases in basal area, especially of beech, indicate that BBD is likely influencing mortality in the BBDMIAS stands. The plots established in 2001 were successful in displaying changes in the spread of BBD. Due to the proliferation of BBD symptoms observed in 2012, monitoring of these plots may have to undergo a change in methodology to detect changes in disease rather than simply presence or absence. Therefore, continued sampling is prudent but must additionally utilize a finer-scale approach particularly with beech scale distribution and $N$. faginata sampling. 


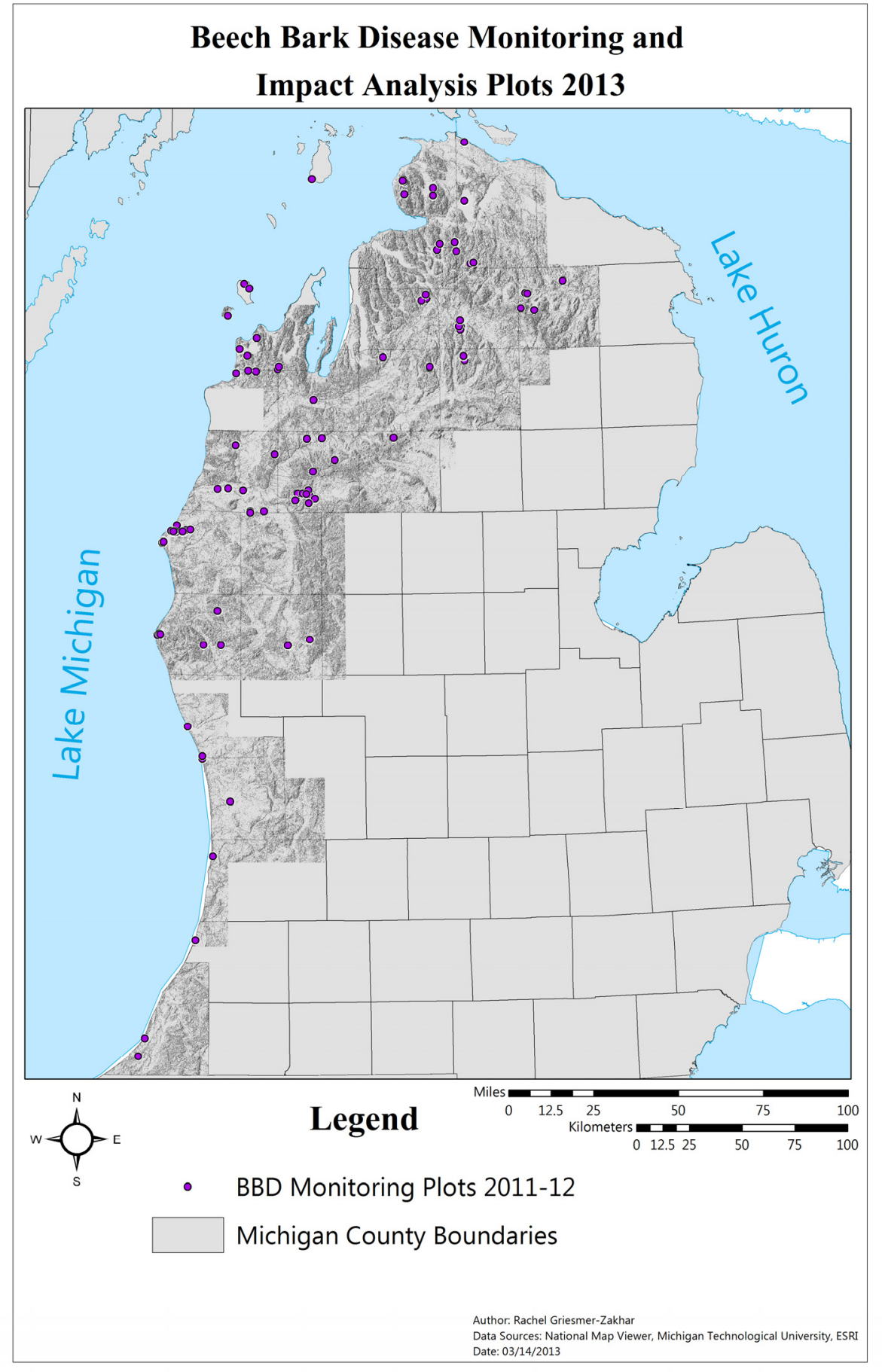

Figure 2.1: Geographic locations of BBDMIAS plots established in 2001 illustrated by purple dots. The plots total 101 and encompass 22 counties in the western, northern and central portions of Lower Michigan. Data sources courtesy of Michigan Tech University, USGS National Map Viewer and Economic Social Research Institute Inc. (ESRI). 


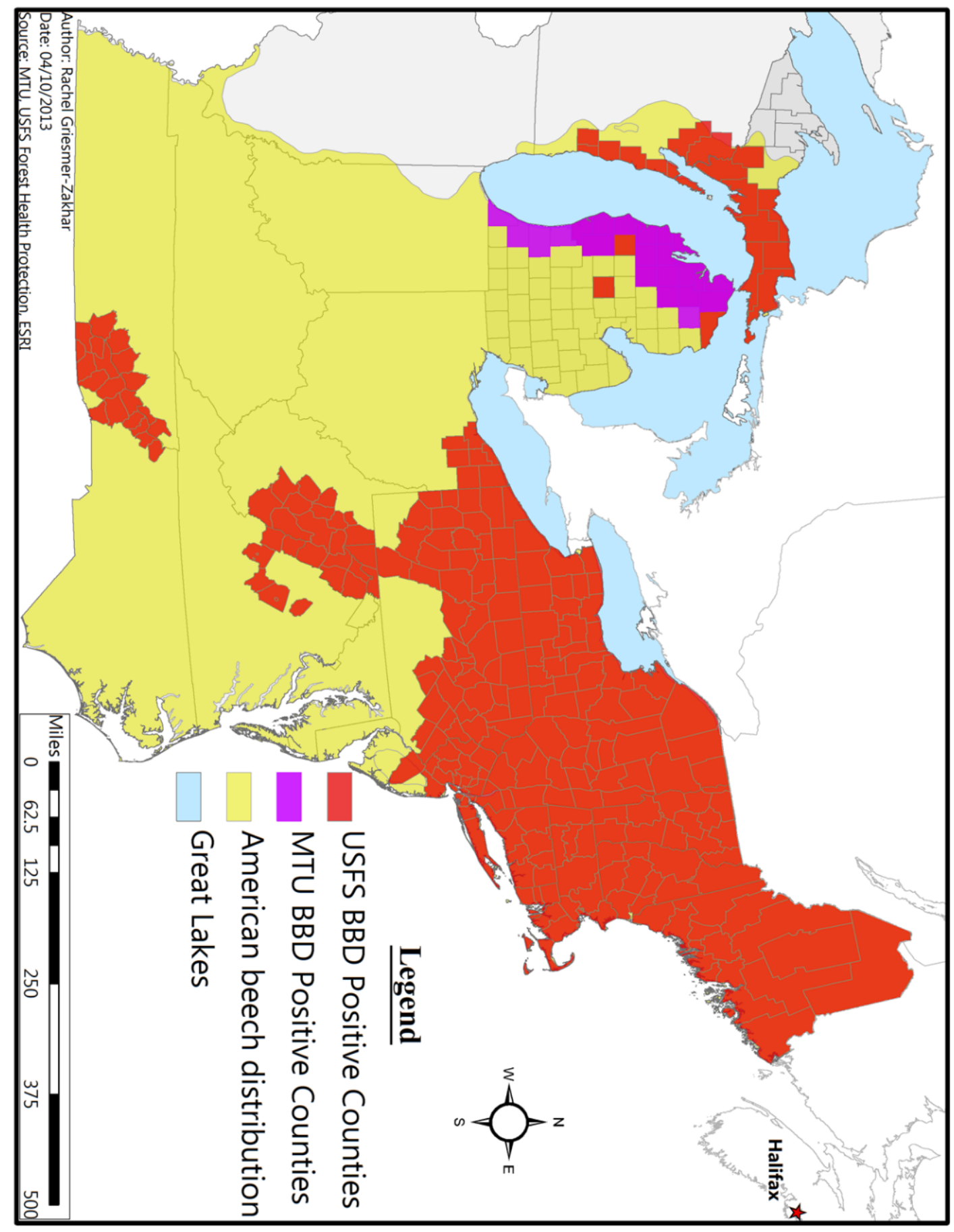

Figure 2.2: Geographic map of beech bark disease distribution in the northeastern United States as of 2013 (red coloration) versus total distribution of American beech ( $F$. grandifolia) in green. Purple areas correspond to counties in Michigan which contained BBDMIAS plots which were positive for beech bark disease following 2011-2012 surveys. Data sources courtesy of Michigan Tech University, U.S. Forest Service Forest Health Protection, and ESRI. 
Table 2.1: Observed damage frequencies in Michigan beech bark disease monitoring and impact analysis plots in 2011-2012 defined as the cumulative number of observations per damage $(\mathrm{n})$ on sample beech $(\mathrm{N}$ [number of trees] $=2970)$. A maximum of three damages can be recorded per tree.

Damage Type

Fruiting body or advanced decay

Cracks and seams

Canker/Gall

Open wounds

Broken/dead branches

Loss of apical dominance

Other

Discoloration of foliage

Excessive branching/brooms

Vines in crown

Broken bole or roots

Damaged buds, shoots or foliage

Resinosis/Gummosis

Brooms on roots or bole

\section{Percent Beech Affected}

$20.2 \%$

$6.7 \%$

$5.0 \%$

$4.5 \%$

$2.8 \%$

$1.0 \%$

$0.8 \%$

$0.6 \%$

$0.3 \%$

$0.2 \%$

$0.1 \%$

$0.1 \%$

$0.1 \%$

$0.1 \%$

n

600

200

146

133

84

30

24

17

8

5

4

2

2

2 


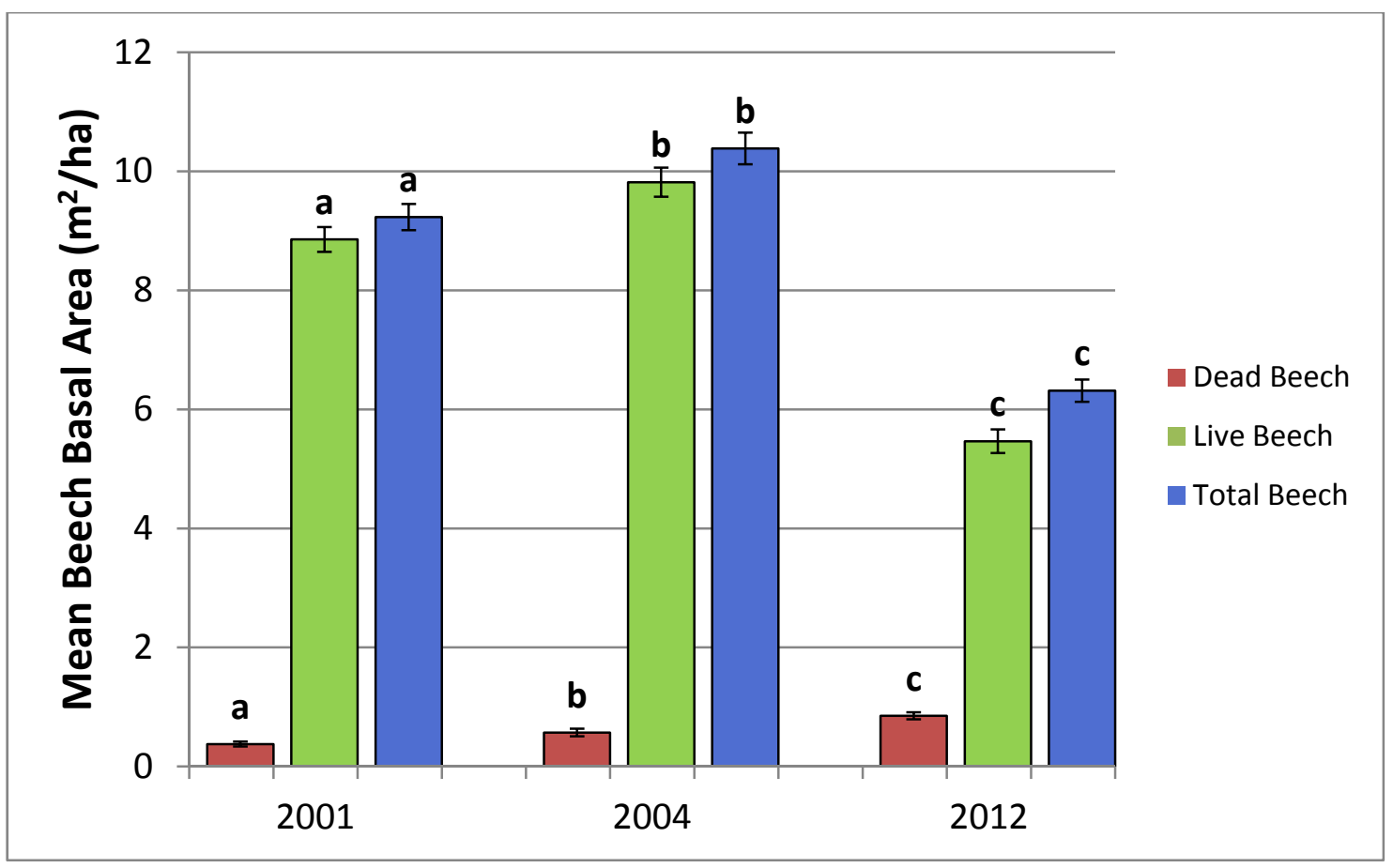

Figure 2.3: The proportion of dead (red bars), live (green bars) and total (blue bars) beech $(F$. grandifolia $)$ mean basal area $\left(\mathrm{m}^{2} / \mathrm{ha}\right)$ measured in BBDMIAS plots in 2001 , 2004 and 2012. Different lower case letters for each of the corresponding colored bars indicate significant differences between years $(\mathrm{p}<0.05)$. Error bars represent standard error of the mean. 


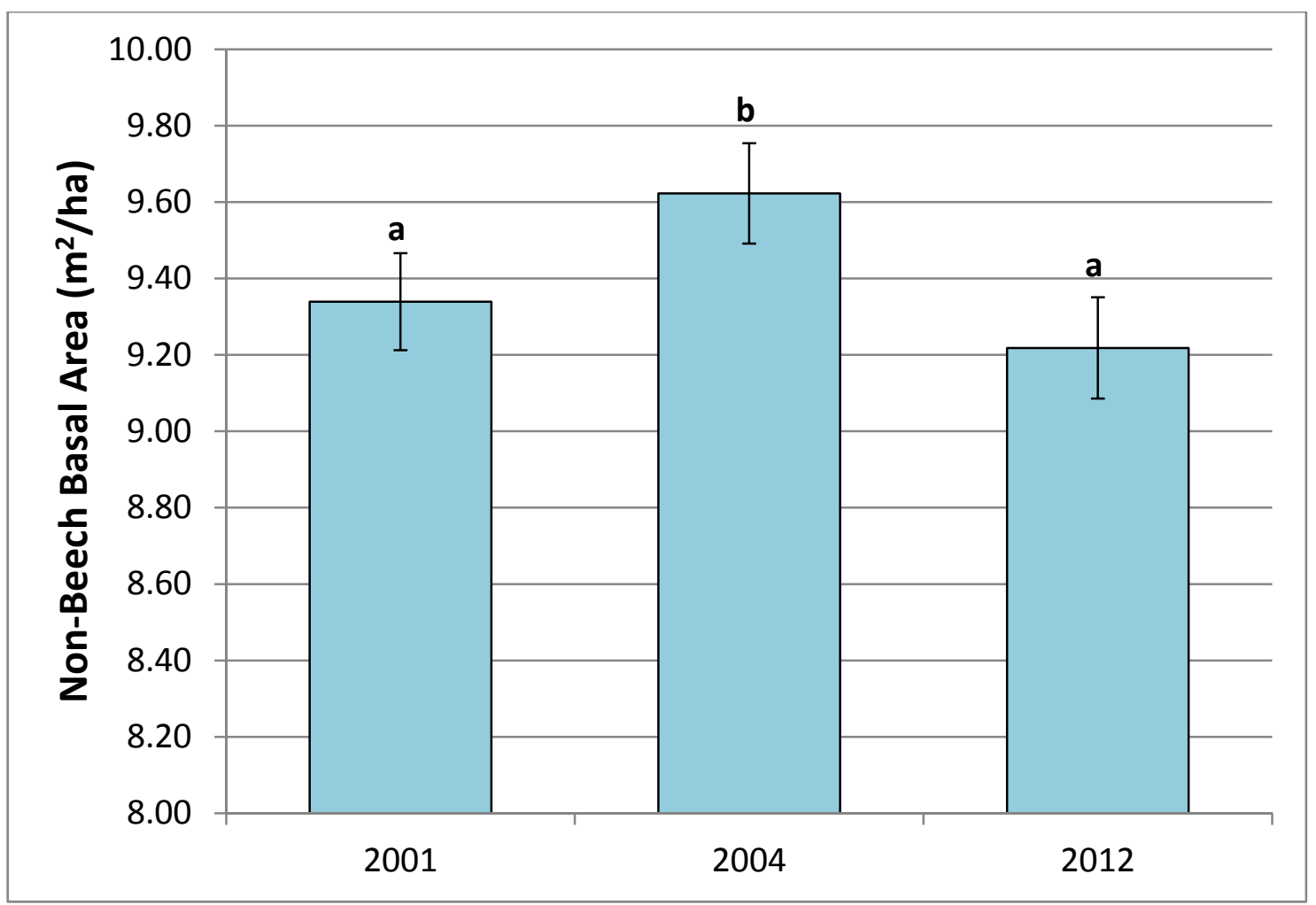

Figure 2.4: Mean basal area $\left(\mathrm{m}^{2} /\right.$ ha) of all species other than beech surveyed in 2001 , 2004 and 2012 in beech bark disease monitoring and impact analysis plots. Different lower case letters indicate significant differences $(p<0.05)$. Error bars represent standard error of the mean. 


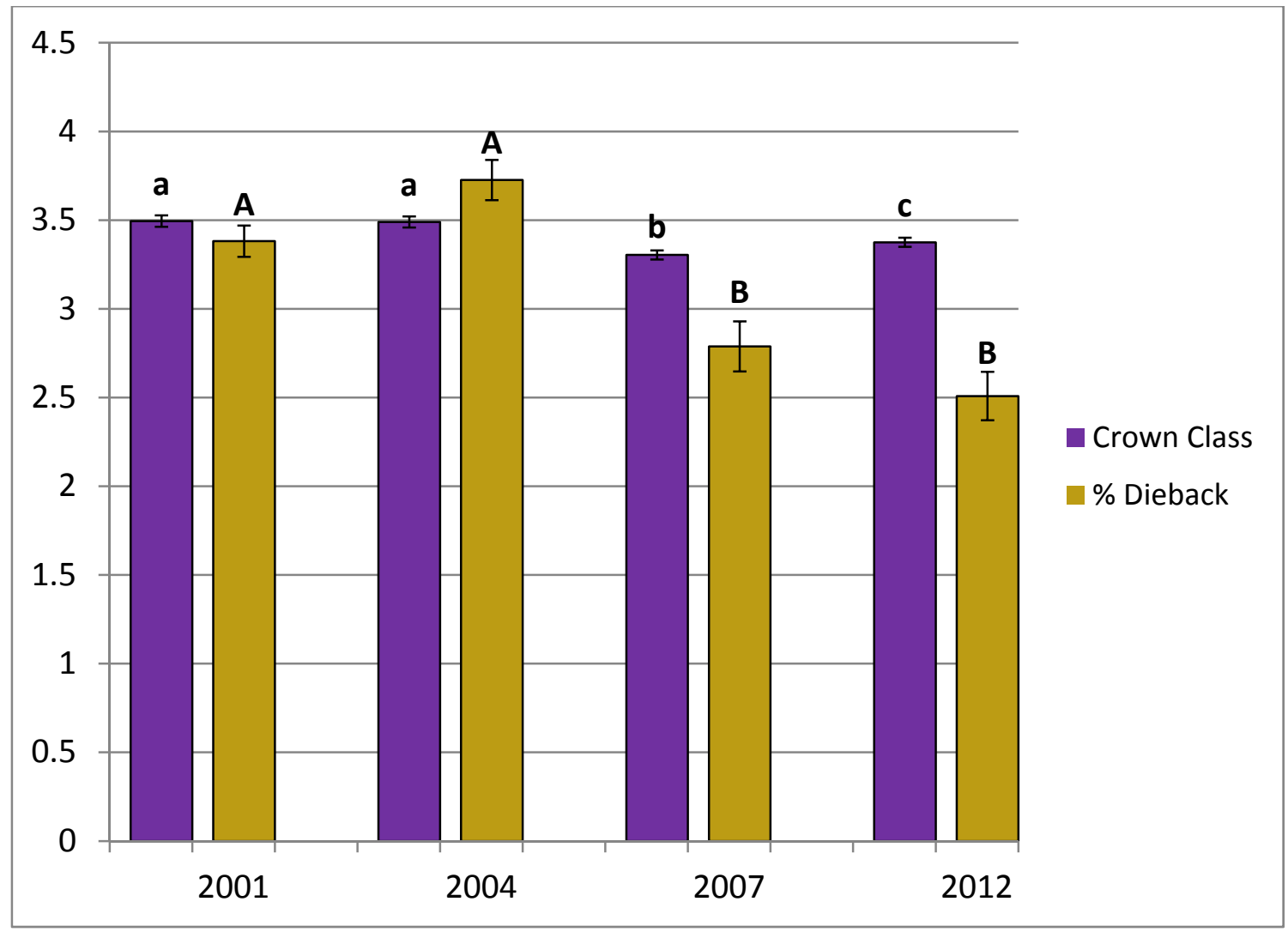

Figure 2.5: Mean beech crown class (purple bars) and percent dieback (yellow) in the beech bark disease monitoring plots in 2001-2012. Significant differences between years of dieback are indicated by different upper case letters. Different lower case letters indicate significant differences in crown dieback across years $(p<0.05)$. Error bars represent standard error of the mean. 


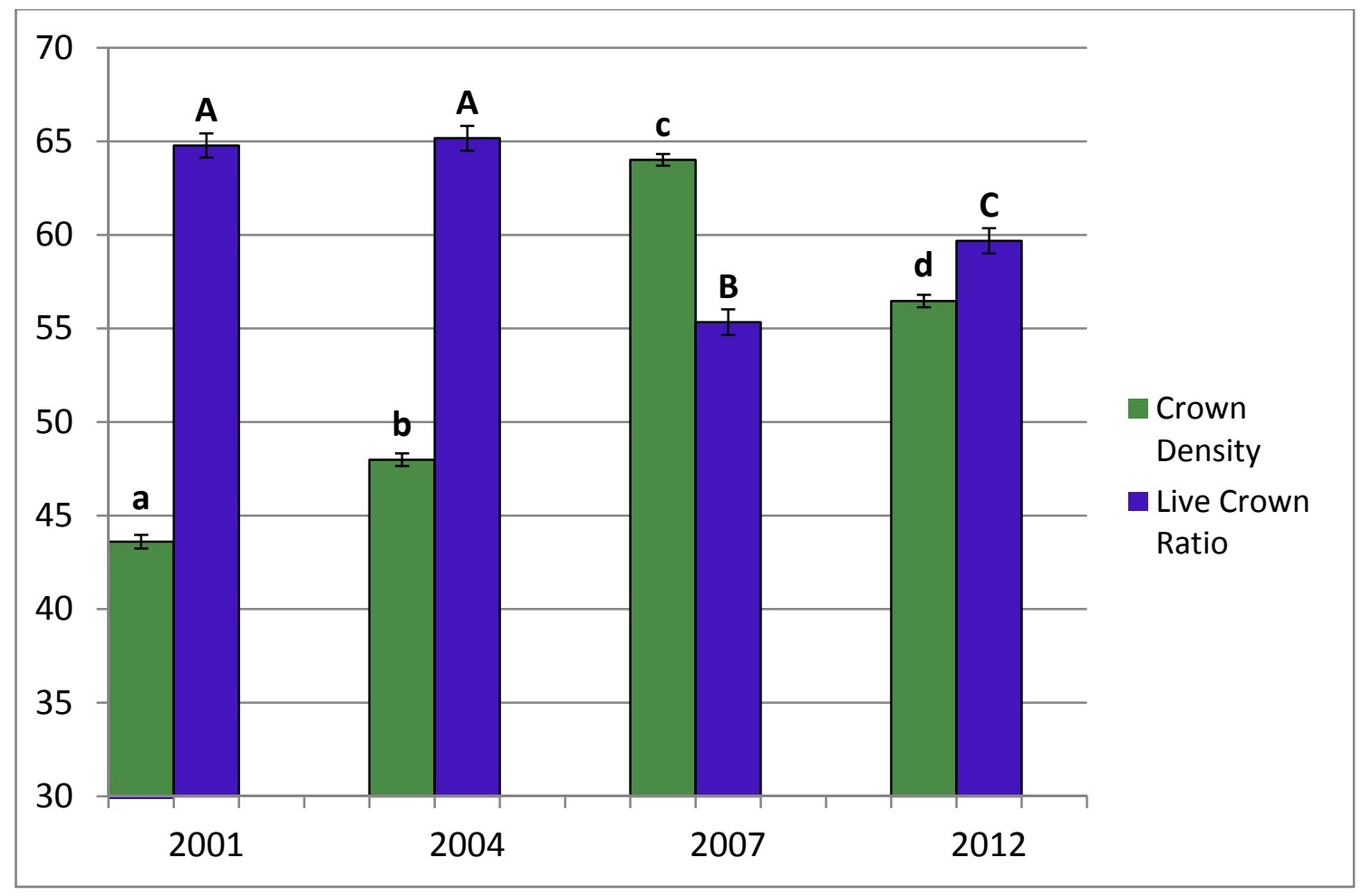

Figure 2.6: Mean crown density (green bars) and uncompacted live crown ratio (blue bars) measured in BBDMIAS plots from 2001-2012. Significant differences in crown density are indicated by different lower case letters $(\mathrm{p}<0.05)$; significant differences in live crown ratio are designated by different capital letters $(p<0.05)$. Error bars represent standard error of the mean. 




Figure 2.7: Mean diameter at breast height (DBH) in $\mathrm{cm}$ of sample beech trees from 2001-2012 in BBDMIAS plots in Lower Michigan. Significance between years is indicated by different lower case letters $(p<0.05)$. Error bars represent standard error of the mean. 




Figure 2.8: Mean foliage transparency of sample beech measured in BBDMIAS plots from 2001-2012. Significant differences between years are dictated by different lower case letters $(p<0.05)$. Error bars represent standard error of the mean. 


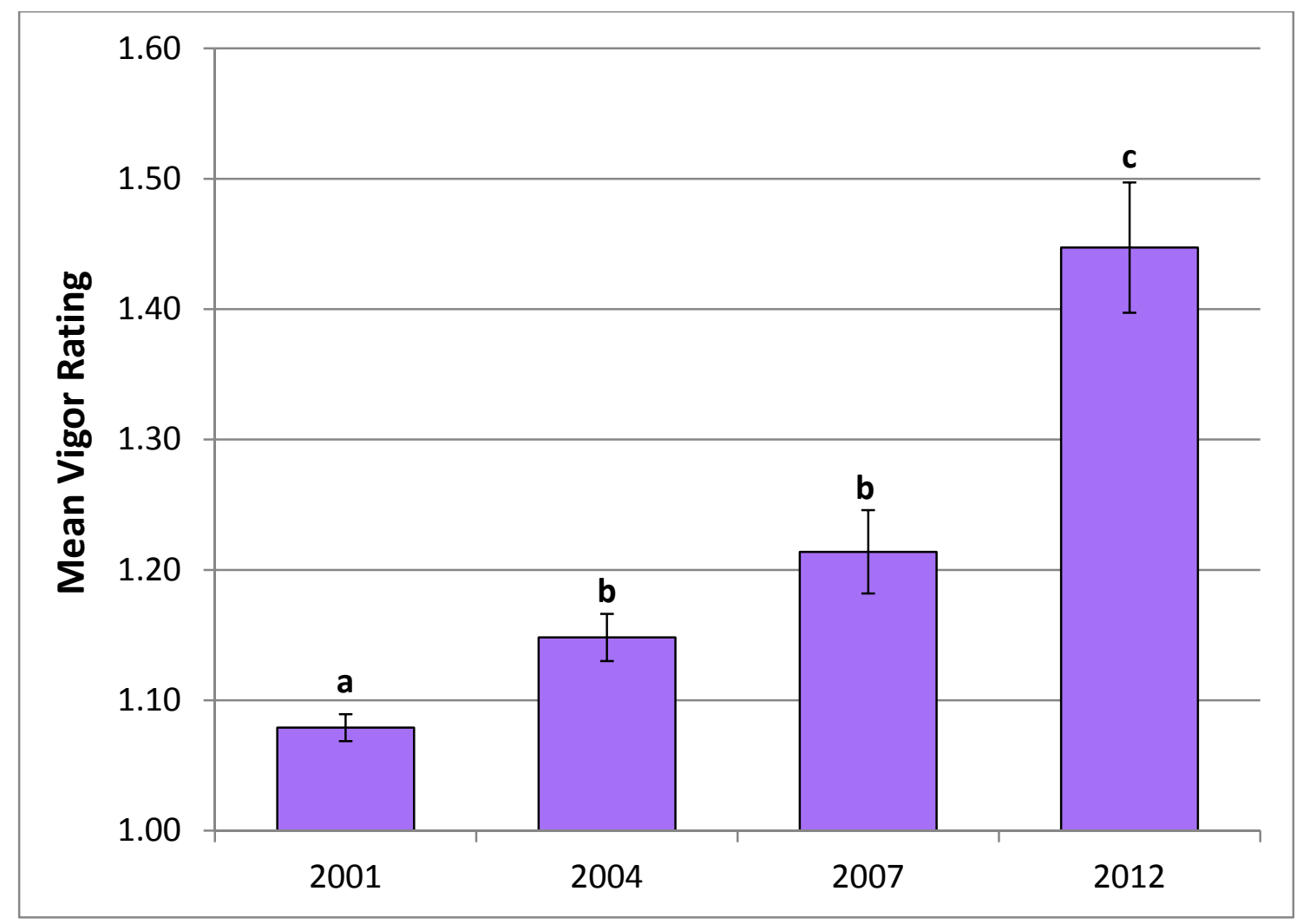

Figure 2.9: Mean vigor rating of sample beech assessed in 2001-2012 in BBDMIAS plots in the Lower Peninsula of Michigan. Significant differences between years are indicated by different lower case letters $(p<0.05)$. Error bars represent standard error of the mean. 
Table 2.2: Spatial exploratory regression analysis on the influence of $C$. fagisuga directional colonization in BBDMIAS plots and slope (rates of elevation change) on beech dieback from 2001-2012. Percent cover of beech scale in each cardinal direction was analyzed with dieback and an associated $\mathrm{R}^{2}$ value and significance level are shown for each relationship. Low $\mathrm{R}^{2}$ values (ranging from 0-1.0) indicate a non-influential relationship between the variables.

2004

\begin{tabular}{lccc} 
Year & Modeled Variables & $\mathbf{R}^{\mathbf{2}}$ & p-value \\
\hline $\mathbf{2 0 0 1}$ & North beech scale & - & - \\
& East beech scale & 0.02 & 0.01 \\
West beech scale & 0.01 & 0.01 \\
South beech scale & 0.01 & 0.01 \\
$\mathbf{2 0 0 4}$ & Slope & - & - \\
& North beech scale & 0.03 & 0.01 \\
& East beech scale & 0.03 & 0.01 \\
West beech scale & 0.04 & 0.01 \\
$\mathbf{2 0 0 7}$ & South beech scale & - & - \\
& Slope & - & - \\
& North beech scale & 0.05 & 0.05 \\
East beech scale & - & - \\
& West beech scale & 0.02 & $>0.10$ \\
South beech scale & 0.01 & 0.1 \\
$\mathbf{2 0 1 2}$ & Slope & 0.05 & 0.01 \\
& North beech scale & - & - \\
& East beech scale & 0.01 & 0.01 \\
West beech scale & - & 0.00 \\
South beech scale & - & - \\
& Slope & 0.01 & 0.01
\end{tabular}





Figure 2.10: Spatial interpolation of average scale densities in the BBDMIAS plots in $2001(A)$ and $2012(B)$. Areas of red, yellow and orange indicate high predicted values of average $C$. fagisuga densities. Areas in blue correspond to projected areas of low scale density. In 2012, incidence of mortality is symbolized by red Xs. Data sources courtesy of Michigan Tech University and USGS National Map Viewer. 


\section{Literature Cited}

Austin, M.P., 2002. Spatial prediction of species distribution: an interface between ecological theory and statistical modelling. Ecological Modelling 157, 101-118.

Burns, R.M., Honkala, B.H., 1990. Silvics of North America: 2, Hardwoods. U.S. Department of Agriculture, Forest Service, Washington, DC.

Cale, J.A., McNulty, S.A., Teale, S.A., Castello, J.D., 2013. The impact of beech thickets on biodiversity. Biological Invasions 15, 699-706.

Chang, K., 2012. Introduction to Geographic Information Systems. McGraw Hill.

Dübeler, A., Voltmer, G., Gora, V., Lunderstädt, J., Zeeck, A., 1997. Phenols from Fagus sylvatica and their role in defense against Cryptococcus fagisuga. Phytochemistry $45,51-57$.

Ehrlich, J., 1934. The beech bark disease: A Nectria disease of Fagus, following Cryptococcus fagi (Baer.). Canadian Journal of Research 10, 593-692.

ESRI, 2012. ArcGIS Desktop. In. Environmental Systems Research Institute, Redlands, California.

Garnas, J.R., Ayres, M.P., Liebhold, A.M., Evans, C., 2011. Subcontinental impacts of an invasive tree disease on forest structure and dynamics. Journal of Ecology 99, $532-541$

Garnas, J.R., Houston, D.R., Twery, M.J., Ayres, M.P., Evans, C., 2012. Inferring controls on the epidemiology of beech bark disease from spatial patterning of disease organisms. Agricultural and Forest Entomology, 1-11. 
Gavin, D.G., Peart, D.R., 1993. Effect of beech bark disease on the growth of American beech (Fagus grandifolia). Canadian Journal of Forest Research 23, 1566-1575.

Houston, D.B., Houston, D.R., 2000. Allozyme genetic diversity among Fagus grandifolia trees resistant or susceptible to beech bark disease in natural populations. Canadian Journal of Forest Research 30, 778-789.

Houston, D.R., 1975. Beech Bark Disease: The Aftermath Forests are Structured for a New Outbreak. Journal of Forestry 73, 660-663.

Houston, D.R., Parker, E.J., Lonsdale, D., 1979. Beech bark disease: Patterns of spread and development of the initiating agent Cryptococcus fagisuga. Canadian Journal of Forest Research 9, 336-344.

Koch, J.L., Carey, D.W., Mason, M.E., Nelson, C.D., 2010. Assessment of beech scale resistance in full- and half-sibling American beech families. Canadian Journal of Forest Research 40, 265-272.

Krabel, D., Petercord, R., 2000. Genetic diversity and bark physiology of the European beech (Fagus sylvatica): A coevolutionary relationship with the beech scale (Cryptococcus fagisuga). Tree Physiology 20, 485-491.

Leak, W.B., 2006. Fifty-Year Impacts of the Beech Bark Disease in the Bartlett Experimental forest, New Hampshire. Northern Journal of Applied Forestry 23, 141-143.

Morris, A.B., Small, R.L., Cruzan, M.B., 2002. Investigating the relationship between Cryptococcus fagisuga and Fagus grandifolia in Great Smoky Mountains National Park. Southeastern Naturalist 1, 415-424. 
O'Brien, J.G., Ostry, M.E., Mielke, M.E., Mech, R., Heyd, R.L., McCullough, D.G., 2001. First Report of Beech Bark Disease in Michigan. Plant Disease 85, 921921.

Papaik, M.J., Canham, C.D., Latty, E.F., Woods, K.D., 2005. Effects of an introduced pathogen on resistance to natural disturbance: beech bark disease and windthrow. Canadian Journal of Forest Research 35, 1832-1843.

Petrillo, H.A., Witter, J.A., Thompson, E.M., 2004. Michigan beech bark disease monitoring and impact anlaysis system. In, Beech Bark Disease Symposium, Saranac Lake, NY, pp. 48-51.

Schomaker, M.E., Zarnoch, S.J., Bechtold, W.A., Latelle, D.J., Burkman, W.G., Cox, S.M., 2007. Crown-condition classification: A guide to data collection and analysis. In. U.S. Department of Agriculture, Forest Service, Southern Research Station, Asheville, North Carolina, p. 78.

Shigo, A.L., 1964. Organism interactions in the beech bark disease. Phytopathology 54, 263-269.

Wainhouse, D., 1980. Dispersal of first instar larvae of the felted beech scale Cryptococcus fagisuga. Journal of Applied Ecology 17, 523-532.

Zar, J.H., 2010. Biostatistical Analysis, Fifth Edition. In: Lynch, D. (Ed.). Prentice Hall, Upper Saddle River, New Jersey. 


\section{Chapter 3:}

\section{Fungal endophyte incidence and potential function within American}

\section{Beech (Fagus grandifolia) and associated antagonism of Neonectria}

\section{faginata. $^{2}$}

Abstract- American beech (Fagus grandifolia) has been dramatically affected by an exotic disease complex of a beech scale insect (Cryptococcus fagisuga) and a pathogenic ascomycete (Neonectria faginata) called beech bark disease (BBD) which has caused widespread mortality in North America. Resistance to BBD has been documented in a small proportion of $F$. grandifolia populations and resistant beech were found in Michigan following surveys in 2011 and 2012. Cambium tissue was sampled from resistant and susceptible beech to extract and identify the associated cambium-inhabiting endophytes. These fungal endophytes were grown with Neonectria to determine if any interaction occurred in vitro. Endophytes were identified primarily as Ascomycetes and Deuteromycetes and the most frequently isolated fungi included Chaetomium globosum, Neohendersonia kickxii and Fusarium flocciferum. Some of these species including $C$. globosum exhibited cellulose degradation and decay potential following a soil wood block decay test. $N$. faginata in antagonism trials showed significant growth reduction when paired with three beech fungal endophytes. The result of the antagonism trial and decay tests indicate that $N$. faginata may be a relatively poor competitor in vivo and has limited ability to degrade cellulose, common attributes of an obligate pathogen.

\footnotetext{
${ }^{2}$ The material in this chapter is in preparation for journal submission.
} 


\section{Introduction:}

American beech (Fagus grandifolia Ehrh.) has been dramatically affected by a disease complex of an exotic beech scale insect (Cryptococcus fagisuga Lind.) and a pathogenic ascomycete (Neonectria faginata (M.L. Lohman, A.M.J. Watson \& Ayers) Castl. \& Rossman) called beech bark disease (BBD) since the late 1800s (Shigo, 1964). The disease which originated in Europe has demonstrated its potential for widespread mortality in F. grandifolia since its introduction to Halifax, Nova Scotia (Shigo, 1964; Houston, 1994a; Gwiazdowski et al., 2006). The disease was discovered in Michigan in 2000 and had spread to 14 counties in the Lower Peninsula and 8 in the Upper Peninsula by 2009 (O'Brien et al., 2001; Wieferich et al., 2011). A continuation of the survey of BBD within long-term monitoring plots in Michigan in 2012 revealed widespread dispersal of the disease in 22 counties. Resistance to BBD has been documented in a small proportion of $F$. grandifolia populations (Houston, 1983, 1994a). Management of beech after disease introduction has focused on removing affected beech and retaining resistant trees (Brandt, 1964; Heyd, 2005). The mechanisms of resistance have been studied more extensively in Europe where the disease has been present for over a century and implicate production of certain secondary metabolites and genetic predisposition which negatively affect beech scale proliferation (Houston et al., 1979; Wainhouse and Deeble, 1980; Krabel and Petercord, 2000). Findings in North America have focused on the genetic influence of resistance (Houston and Houston, 2000; Ramirez et al., 2007; Koch et al., 2010). 
Fungal endophytes are a poorly understood aspect of microbial ecology in forestry (Bills, 1995; Vicari, 1997). Endophytes are microorganisms which live within and infect healthy host tissues and remain asymptomatic for most, if not all of their life cycle (Carroll, 1988; Petrini, 1991; Wilson, 2000). Fungal endophytes can have various ecological functions as saprobes and pathogens to symbionts and mutualists. Symbiotic or mutualistic endophytic fungi are the most interesting in terms of disease management. The well-studied endophytes within grasses, those within the family Clavicipitaceae, exhibit antagonism against insect pests (Carroll, 1988; Christensen and Latch, 1991). The mutualistic relationship between the plant and endophytes was perpetuated by dissemination of fungal spores within the seeds of the plant so that future generations would germinate with the endophytes referred to as a constitutive mutualism (Carroll, 1988).

The majority of endophytes within plants such as trees must recolonize healthy host tissue in subsequent generations or may enter via wounds (Toti et al., 1992; Wilson, 2000). Many factors influence the composition of the endophytic flora of host species including environment, nutrients, season, host defense and geographic location (Carroll, 1988; Fisher et al., 1994; Carroll, 1995; Sahashi et al., 1999; Hoffman and Arnold, 2008). Fungal endophytes which are isolated frequently usually are host and/or tissue specific (Petrini, 1991; Sahashi et al., 1999). Within tissues, the distribution and diversity varies. In Alnus bark, a greater diversity and quantity of endophytes was observed in bark than in xylem or root tissues (Fisher and Petrini, 1990). Tissue specificity has also been observed in beech but most studies focus on communities in 
leaves or twigs because leaves are the primary infection location and generally have a high turnover rate in deciduous species (Sahashi et al., 1999; Wilson, 2000; Danti et al., 2002).

There are several, repeated instances where fungal endophytes had an antagonistic effect on forest disease pests or pathogens. In Ulmus, an endophyte Phomopsis oblonga Desm. inhibited reproduction of the Dutch elm disease vector beetle (Carroll, 1988). Fungal endophytes can also impact defoliating insects by initiating early leaf senescence (Wilson, 2000). A compound produced by an endophyte within balsam fir has been found to inhibit spruce budworm growth (Miller et al., 2002). Fungal pathogens can also be impacted by endophytic fungi. Hypoxylon, a pathogen of black cottonwood and willow, was inhibited by two non-specific endophytic saprophytes (Bier and Rowat, 1962). Endophytes present in Pinus monticola Douglas ex D. Don reduced the severity of white pine blister rust (Ganley et al., 2008). In beech, N. faginata spore production has been reduced in vivo when interaction with Gonatorrhodiella highlei A.L. Sm. occurs. This fungus parasitizes the pathogen on beech bark (Shigo, 1964). It has been suggested that the promotion of inhibitory or antagonistic compounds in interacting fungi become more pronounced once resources are depleted (Rayner et al., 1994). A similar situation may arise when insects and fungi compete for the same host resources, even if indirect.

Beech bark disease in Europe was found to be influenced by bark mycoflora including a lichen, Dichaena rugosa (L.)Fr. (Houston et al., 1979; Speer and Butin, 1980). Fungal endophytes that inhabit cambium tissue in beech may affect BBD 
incidence or severity. The possibility of direct antagonism of the insect or pathogen involved in the disease is atypical, but natural inhibitory compounds may be produced by even cosmopolitan endophytic fungi that could suppress growth (Bills and Polishook, 1992; Wilson, 2000).

The ecological niche of endophytes within forest trees have not been examined thoroughly (Wilson, 2000). Enzymatic capability of fungi, especially cellulose degradation, can determine the effect of the fungus on its host. Ecologically, the ability to degrade cellulose can suggest the fungus is a facultative pathogen or a wood decay species.

Cellulose azure, a dyed cellulose powder, is an inexpensive, qualitative means to detect cellulase activity based on proliferation of blue dye through a colorless agar medium (Pointing, 1999). Additionally, the detection of some white rot fungi (those possessing lignin peroxidases) is possible due to subsequent bleaching of the liberated dye (Archibald, 1992).

Ascomycetes or microfungi also have the ability to decay wood as soft rotters (Worrall et al., 1991). Soft rot species degrade cellulose from actively growing hyphae. Soft rot usually occurs at the surface of the wood and creates cavities in between lignin molecules unlike white or brown rot. Soil block decay testing is used to determine the relative ability of a species to reduce the weight of a standardized size of wood block under ideal conditions for fungal growth. These tests were developed to test the effectiveness of different wood preservatives (Duncan, 1958). The nature of facultative 
saprophytes (brown, white or soft rotters) can be deduced based on these decay test results.

Several studies have isolated endophytes, synonymously described as microfungi from within beech cambium (Cotter and Blanchard, 1982; Fernandez and Boyer, 1989; Danti et al., 2002; Baird et al., 2007). In the aftermath zone in the United States, fungal endophyte diversity within cambium tissue was compared between resistant or nonaffected and susceptible beech trees (Cotter and Blanchard, 1982; Baird et al., 2007). The number and diversity of species isolated from beech cambium has not been consistent. These variations in observed diversity of endophytes may have been influenced by selection criteria of sampled susceptible beech, the size and location of tissue samples, geographic location of hosts and the length of time between collection and isolation (Fisher et al., 1994; Carroll, 1995; Baird et al., 2007; Hoffman and Arnold, 2008). None of these studies suggested endophytic fungi have a role in beech bark disease resistance.

We hypothesized that trees resistant to beech bark disease would have different endophyte assemblages than susceptible trees and influence resistance mechanisms; and endophytes in resistant trees would be antagonistic toward Neonectria in vitro. The objectives of this study were to i) establish the relative diversity of endophytes in beech cambium tissue in both resistant and susceptible trees ii) isolate and identify Neonectria faginata in pure culture iii) identify endophytes from beech cambium iv) conduct decay tests on beech cambium endophytes to establish a rough measure of their function and v) grow isolated beech endophytes individually with Neonectria to test for antagonism. 


\section{Materials and Methods}

\section{Endophyte Isolation and Classification}

The locations of resistant beech were determined and located near a plot monitoring system in upper and lower peninsulas of Michigan. An associated susceptible beech tree was located within 36 meters of resistant trees and was considered as a single population. The majority of trees sampled were located in the eastern Upper Peninsula of Michigan (Luce County), with several more isolated from populations in the Lower Peninsula (Emmet County).

Samples of beech cambium were collected using a one-inch diameter arch punch (General Tools, New York City, NY) hammered into the bole of a selected population of resistant and susceptible beech trees approximately 1.5 meters from the ground. Cambium samples were taken from the side of the tree opposite its tag (in trees in the Upper Peninsula), avoiding lesions, branch junctures and callous material.

A total of 60 samples were collected in July and August of 2011. Before and after use, a new cotton wipe soaked in $70 \%$ ethanol was used to sterilize the arch punch. Each cambium sample or bark plug was placed into individually labeled zip-top bags and placed in a cooler. Samples were stored in a refrigerator until processing within five days of collection. In the laboratory, the outer millimeter of bark was removed from each of the plugs with a razor blade sterilized in 85 percent ethanol. Two-three mm cubes were cut from the bark discs such that they came from the central portion of the disc. 
To reduce the influence of incidental non-endophytic fungi, the cambium cubes were surface sterilized using 10 percent Clorox $^{\circledR}$ for 15 seconds and rinsed with sterile $\mathrm{H}_{2} \mathrm{O}$ for 30 seconds (Schulz et al., 1993). Cubes were removed from the water bath with sterile forceps and blotted on clean paper towel to remove surface water.

Cambium cubes were placed onto $60 \mathrm{~mm}$ petri plates with $2 \%(\mathrm{w} / \mathrm{v})$ malt extract agar amended with 400ppm streptomycin. Three replicate plates were prepared for each tree sample, with three cambium cubes from the same tree in each plate placed in an equidistant arrangement. Cultures were allowed to grow $14-20$ days at $22-24^{\circ} \mathrm{C}$, after which pure cultures were transferred onto fresh $2 \%$ malt extract plates (without antibiotic). Preliminary observations were made after 14 days and compared with observations in pure culture after approximately 20 days to allow cultures to mature. Pure cultures were then classified by morphotype according to both colony growth characteristics and 400x microscopy and given an associated letter and number code. Morphotypes were categorized based on cultural characters and rates of growth, described according to characters listed in the Identification Manual for Fungi from Utility Poles in the Eastern United States (Wang and Zabel 1990). Fungi that originated from a cambium cube were counted as separate isolates only if they differed from others within the same plate.

DNA sequencing was performed on the 14 most commonly isolated fungi and $N$. faginata by the USDA Forest Products Laboratory in Madison, Wisconsin. Representative cultures were grown on agar slants until reaching a harvestable size. To confirm pathogen identity, a representative isolate of $N$. faginata was received from Lisa 
Castlebury (USDA ARS, Beltsville, MD) and was used to compare voucher samples collected from Michigan in culture.

The fungal internal transcribed spacer (ITS) sequences were compared for both forward and reverse directions and integrated to create a single sequence at the Forest Products Laboratory (Madison, WI). The resulting sequences were queried in GenBank to search for similar species using the BLASTn algorithm (Altschul et al., 1997). Each specimen's identity was deduced from a high percentage of query homology and maximum identification percentage. Where uncertainties arose, cultural characteristics were used as a supplement to arrive at the final proposed identity based on the closest relative in GenBank and using host indices and other references. Despite the availability of GenBank sequences, some isolates resulted in no genus or species matches. These isolates' sequences were then compared to determine similarities to deduce a final identity if possible.

\section{Cellulase Analysis}

Yeast extract agar without carbohydrates, a modification of Pettersson's medium (Smith, 1977) was prepared as follows: $3 \mathrm{~g}$ yeast extract (Difco, Detroit MI), $15 \mathrm{~g}$ agar and $1 \mathrm{~L}$ of distilled water. Approximately $10 \mathrm{~mL}$ of the melted yeast agar was poured into $18 \mathrm{~mm}$ x $145 \mathrm{~mm}$ test tubes. In a separate flask, $0.5 \mathrm{~g}$ of cellulose azure powder (Sigma-Aldrich, St. Louis MO) was mixed with $25 \mathrm{~mL}$ of the melted yeast extract agar. The tubes and cellulose azure agar were autoclaved for 15 minutes. 
Once agar in the tubes had solidified, approximately one $\mathrm{mL}$ of the cellulose azure agar was pipetted from a sterile $10 \mathrm{~mL}$ pipette into each tube. The resulting tubes had a small layer of the insoluble cellulose azure on top of the clear yeast agar.

A total of 16 endophyte morphotypes were tested on cellulose azure based on high frequency of isolation and are shown in Table 3.3. Additionally a field collected isolate of $N$. faginata ( $\left.\mathrm{RG}_{-} 01\right)$, the primary pathogen causing beech bark disease was also tested (Castlebury et al., 2006).

Coniophora puteana (Schumach.) P. Karst. DR_460, a brown rot fungus, and Pycnoporus cinnabarinus (Jacq.) P. Karst. DR_430, a white rot fungus were used as positive controls, both of which were able to degrade cellulose. Laccaria bicolor (Maire) P.D.Orton DR_170, an ectomycorrhizal fungus, was used as a negative control as it lacks cellulase enzymes.

Each isolate and the controls were grown on $2 \%$ malt extract agar for two weeks. A flame-sterilized five mm diameter cork borer was used to extract an agar plug containing mycelium from the edge of an actively growing colony. The agar pieces were placed mycelium-side down on top of the agar in each tube. Inoculated tubes were incubated in the dark at $22-24^{\circ} \mathrm{C}$, observed and recorded at nine and 18 days.

Cellulase activity was estimated using an arbitrary qualitative classification system corresponding to the level of dye progression in the cellulose agar tube. A rating of 0 was equivalent to no dye liberation and 10 indicated high cellulase activity and the darkest blue dye liberation. Wood Decay Capability of Endophytes 
Several beech logs were obtained from fuelwood in Munising Township, Alger County in the Upper Peninsula of Michigan. The source tree itself had no sign of beech bark disease but the disease was present in the area (Bruce Leutscher, pers. comm.). The tree was removed in June 2011, bucked in September 2011 and stored on uncovered pallets until winter when the pile was covered with a tarp. The wood for the decay test was collected in March 2012, cut into 14mm cubes and autoclaved for 20 minutes at $125^{\circ} \mathrm{C}, 103 \mathrm{kPa}$. The blocks were dried to overnight dry weight at $40^{\circ} \mathrm{C}$ in a drying oven and weighed.

Five endophytes: RG_136 (Chaetomium globosum Kunze), RG_131 (Fusarium flocciferum Corda), RG_100, RG_101 (C. puteana), RG_118 and RG_107 (Phaeoacremonium sp.) were selected based on highest frequency of isolation and cellulase activity from the cellulose azure test. Two positive controls, Gloeophyllum sepiarium (Wulfen) P. Karst. DR_436, a brown rot fungus and Trametes versicolor (L.) Lloyd MAD697, a white rot fungus, the beech bark disease pathogen Neonectria faginata and a negative control (RG_104) were also used. A total of 100 jars, 10 for each isolate, were filled with $100 \mathrm{~g}$ of soil dried at $50^{\circ} \mathrm{C}, 30 \mathrm{~mL}$ of distilled water and a $5 \times 32 \times 20 \mathrm{~mm}$ aspen feeder strip on top of the soil surface. The jars were autoclaved for 30 minutes at $125^{\circ} \mathrm{C}, 103 \mathrm{kPa}$.

Each fungus was grown on $15 \times 100 \mathrm{~mm}$ petri plates with approximately $20 \mathrm{~mL}$ of $2 \%$ malt extract agar for 14 days in a controlled humidity chamber at approximately $27^{\circ} \mathrm{C}$ and $85 \%$ relative humidity. Once the plate was covered in mycelia, the agar was sliced into $0.5 \times 2 \mathrm{~cm}$ strips. Each strip was placed into a soil-filled jar on top of the feeder strip. 
The beech blocks were added immediately on top of the inoculum, pressing down to achieve good contact between the block and the agar strip. A plastic lid with a $5 \mathrm{~mm}$ hole punched from the middle and covered with medical tape for air exchange was placed on the jars.

The jars were placed in a controlled humidity chamber for 10 weeks at approximately $27^{\circ} \mathrm{C}, 85 \%$ relative humidity. After 10 weeks, observations were noted on the colonization of the blocks, removed from the jar which were dried in the same method as before inoculation, and weighed again. Percent weight loss was calculated by subtracting the initial block weight from the final weight of the blocks at the end of the 10 week test.

\section{Neonectria Antagonism}

Five isolates that were used in the cellulose azure and decay tests were further analyzed to determine their effect on Neonectria faginata in vitro. $100 \mathrm{~mm}$ petri plates were prepared with $2 \%$ malt extract as described previously (Difco, Detroit MI). Six tests were performed including a control with three replicates each: $N$. faginata growing alone, N. faginata + C. globosum (RG_136), N. faginata + Coniophora puteana (RG_101), N. faginata + Phaeosphaeriaceae sp. (RG_104), N. faginata + Phaeoacremonium spp. (RG_107), and N. faginata + F. flocciferum (RG_131).

Three replicate plates were prepared for each antagonism test with one of each fungal isolate an equal distance apart (Richter et al., 1989). A flame-sterilized 5mm cork borer was used to extract an agar plug from an actively growing margin of each of the endophyte isolates and Neonectria. Two dots were drawn on the underside of each plate so that each agar plug was placed $1.5 \mathrm{~cm}$ apart near the center of the plate. The 
Neonectria control was the exception which only had one dot in the center of the plate to determine the growth of Neonectria alone. Plugs were placed mycelium side down onto the center of the dots drawn on the plates. Each antagonism test plate received one plug of Neonectria and one of the respective endophyte isolate.

The colonies were grown for two weeks in an incubator at $22-24^{\circ} \mathrm{C}$. From the centroid point of each Neonectria colony (the original dot drawn on the plate), four radial measurements of growth were recorded after each week to account for non-circular growth. The longest or maximum radial measurement distal to the endophyte colony was compared with corresponding Neonectria control radii to accommodate for inhibition compensation.

Data Analysis

Differences in radial growth of Neonectria paired with the different isolates were analyzed using SPSS 17 (SPSS Inc. Released 2008. SPSS Statistics for Windows, Version 17.0 Chicago: SPSS Inc.). A multivariate one-way ANOVA was conducted with the different isolate combinations as treatments. Differences between treatments were determined using Scheffé's test (Zar, 2010).

\section{Results}

\section{Endophyte Isolation and Identification}

Forty-one trees out of 60 sampled yielded fungi: 21 from apparently resistant trees and 20 from susceptible trees. From these, 183 colonies were observed from the 180 replicate plates containing the cambium cubes. The rate of false negatives in sampling is 
unknown. 40 morphotypes were described from these isolates and their descriptions are listed in Table 3.1.

Twenty percent of the morphotypes (8) were isolated exclusively from resistant beech an $15 \%$ (7) were found only from susceptible beech. The remaining 55\% were isolated from both. Overall, more colonies were isolated from susceptible beech than from resistant ( $\mathrm{n}=107$ and $\mathrm{n}=76$ respectively).

Average endophyte isolation frequency was low (less than 5\%) because the majority were from single isolates. The most frequently isolated fungus was $C$. globosum (RG_136) which occurred in $9.30 \%$ of the pure cultures obtained from sampled resistant and susceptible beech (Table 3.2). RG_100, RG_103 (Neohendersonia kickxii (Westend.) B. Sutton \& Pollack), RG_139+RG_140 (Coniothyrium fagi Tehon) and F. flocciferium each constituted $6.98 \%$ of isolations. C. puteana, and RG_109 represented $3.49 \%$ of isolations. The frequencies of the remaining isolates (32) including $\mathrm{RG}_{-} 107$ (Phaeoacremonium sp.), RG_108, and RG_104 were isolated in less than 5\% of pure cultures.

Several species which had no direct match in GenBank showed similarities when compared. RG_108 and $\mathrm{RG}_{-} 134$ resulted in a 97\% match of identity. RG_108 and RG_109 resulted in a 92\% similarity match. However, both of these isolates had low query coverage which indicates nucleotides of the compared isolates were not completely aligned and were not the same species and so remain unidentified.

Cellulose Azure 
Most isolates showed at least a small degree of cellulolytic activity. Positive controls, C. puteana DR_460 and P. cinnabarinus DR 430 produced the highest ratings of 10 achieved after only nine days for C. puteana (Table 3.3). Some endophytes had ratings equivalent to the positive controls after 18 days. Only the negative control, $L$. bicolor DR_170 and endophytic isolates $\mathrm{RG}_{-} 103, \mathrm{RG} \_104$ and $\mathrm{RG} \_109$ showed no evidence of cellulose degradation (Table 3.3).

Decay Capabilties of Beech Endophytes

The majority of endophytes resulted in less than $10 \%$ weight loss of beech wood blocks with the exception of RG_101 (C. puteana) a brown-rotting basidiomycete, which exhibited 15.69\% loss (Figure 3.2). Two isolates, $N$. faginata and F. flocciferum showed a negative weight loss (-0.35 and -0.27 respectively) or slight weight gain and correspond to the missing bars in Figure 3.2. The associated weight gain is equivalent to zero weight loss and is often due to absorption of water by the wood block or from residual mycelial mass. Those fungi which produced the greatest weight loss often had completely colonized the beech blocks and underlying feeder strips, especially $T$. versicolor, a white rot fungus. C. puteana (RG_101) produced mycelium extending deep into the soil. The endophytes, including the negative control (RG_104) colonized the aspen feeder strips more extensively than the beech blocks.

Neonectria Antagonism

Neonectria faginata when grown with C. globosum (RG_136), F. flocciferum (RG_131) or C. puteana (RG_101) exhibited significantly reduced mean maximum radial growth than when grown alone after two weeks (Table 3.4). Each of the antagonistic endophyte isolates grew very vigorously but did not grow over Neonectria. 
Phaeosphaeriaceae sp. (RG_104) and Phaeoacremonium sp. (RG_107) had no significant effect on Neonectria growth even after two weeks (Table 3.4).

\section{Discussion}

Unique isolates that were only observed once may or may not be putative endophytes considering the relative rarity of isolation (Carroll, 1995). The overall lack of fruiting structures and plasticity of morphological characters in culture made definitive categorization difficult but is common when working with endophytes (Unterseher and Schnittler, 2010). The dynamic nature of fungal morphology may in fact reflect the isolation method and be unavoidable (Rayner et al., 1995). As a result, the morphotyping procedure may not have accurately reflected species richness of the endophyte community and may have related to the small sample size (Unterseher and Schnittler, 2010). For example, RG_139 and RG_140 were categorized as two morphotypes but DNA sequencing revealed them to be the same species (Table 3.2).

Most species that were identified were Ascomycetes and two were Basidiomycetes (RG_101, Coniophora puteana and RG_114, Trametes versicolor). The rest of the sterile forms whose DNA were not sequenced were suspected Ascomycetes, specifically Coelomycetes, Hyphomycetes and Discomycetes. This is for the most part consistent with other findings that isolated endophytes were considered microfungi (Cotter and Blanchard, 1982; Fernandez and Boyer, 1989; Baird et al., 2007). Cotter and Blanchard (1982) found very few hyphomycetes including no Penicillium nor Trichoderma which were extensively identified in Baird et al. (2007). The suspicion that 
these species, specifically Penicillium were airborne contaminants in the laboratory may have influenced the lack of observation in this current study.

The most frequently isolated endophyte from both resistant and susceptible beech, Chaetomium globosum was identified in the endophytic diversity study by Cotter and Blanchard (1982) though not from Michigan. This species is mostly likely an endophyte within $F$. grandifolia. The remaining frequently isolated endophytes were found in several other studies of beech mycoflora including C. fagi in leaves (Tehon, 1924), $N$. kickxii in cambium (Küffer et al., 2004) and Fusarium sp. in cambium (Cotter and Blanchard, 1982). The use of richer medium, variations of sampling regime (including lack of surface sterilization) and geographic location may have influenced the discrepancy in isolation compared to other studies. The potential spatial relationship of endophytes in relation to host distribution would be an interesting continuation of this study. This pattern has been shown in spatially separated oaks of the same species in Europe where distinct populations of fungal endophytes exist (Fisher et al., 1994). Local environmental conditions may influence fungal incidence which require cool, moist conditions for colonization and dissemination.

While only two extreme classes of beech were sampled for endophyte assemblages, there might be an effect of the gradient of susceptibility. Baird et al. (2007) only collected samples from susceptible beech that had Neonectria perithecia. There might be a greater difference in endophyte frequency between supposed resistant beech and those with confirmed N. faginata presence. The factors that contribute to BBD susceptibility including bark chemistry and its effects on endophyte colonization should be further investigated (Martin et al., 2013). 
The ecological potential for the endophytes to exhibit latent pathogenic characteristics would include the ability to produce compounds that affect the host negatively, including cellulase enzymes (Schulz et al., 1999; Wilson, 2000; Schmidt, 2006). Seven of the tested isolates showed evidence of cellulolytic activity (Table 3.3). Deuteromycetes and Ascomycetes can also be opportunistic soft-rot decay fungi which may explain cellulolytic activity (Wang and Zabel, 1990; Worrall et al., 1991). The relative lack of decay of the remaining endophytic fungi may have been related to the some of the methods of the soil block test. Soft rot fungi require moist conditions and the beech block substrate which was dried to overnight dry weight and may not have contained enough water for adequate decay (Levi and Preston, 1965).

RG_101 (C. puteana), RG_102 (unidentified) and RG_114 (T. versicolor) were presumed to be Basidiomycetes (Table 3.3). RG_114 (T. versicolor) showed evidence of agar bleaching in the cellulose azure test after 18 days, but was not quite comparable to the positive control of the same species (Figure 3.2). RG_102 (unidentified) may have had additional enzymatic activity including possible [lignin] peroxidases which gave the agar medium a green cast (Figure 3.1). The alteration of agar color may have positively skewed the estimate of dye intensity. Though care was taken not to isolate from wounded or necrotic regions of cambium, occurrence of white rot fungi may be attributed to secondary colonization through feeding wounds or other areas of dead cambium (Schmidt, 2006).

Neonectria faginata (RG_01) showed slight cellulolytic activity after 18 days on cellulose azure (Table 3.3) which may offer further insight into its infection mechanism. Neonectria spores enter primarily through feeding wounds created by the scale insect, $C$. 
fagisuga forming adventitious germ tubes which penetrate into cells. Its means of progression through living cambium tissue beyond that is not well understood (Brandt, 1964; Houston, 1994b). Diffuse cellulase production by Neonectria may enable the fungus to erode cell walls and expand colonizable cambium area. Further research should quantify cellulase activity of Neonectria both in vivo and in vitro to discern its mode of infiltration.

When grown together in vitro with beech endophytes, Neonectria growth was significantly reduced when paired with three endophytes. This may not reflect direct antagonism or negative impact on the disease pathogen. However, the observed growth inhibition may offer insight to the ecology of the pathogen. Neonectria may be a poor competitor and relatively ephemeral and overcome by other fungi in cambium tissue, especially in non-ideal conditions. The lack of perithecia in BBD-killed beech may reflect this brief colonization period which would allow other species to colonize the dead tissue (Houston, 1994b). The temporal progression of Neonectria within beech tissues needs further exploration. The three endophyte species that showed growth inhibition were fast growing and vigorous including Chaetomium globosum, Fusarium flocciferum and Coniophora puteana. Antifungal compounds have been isolated from $C$. globosum which were effective in reducing growth of agricultural plant pathogens in vitro and also showed antagonism in vivo (Park et al., 2005). The lack of growth observed in the antagonism test with C. globosum after the second week of measurements might have been influenced by this compound (Table 3.3). The observed reduction in Neonectria growth should ideally be corroborated with an inoculation trial. Results in 
vitro can be markedly different than in within the organism and may not indicate actual inhibition or antagonism (Carroll, 1995).

The application of these fungal endophytes to reduce disease severity may yet be conclusive. Future research is needed not only on fungal endophyte composition but also including whether symbiotic relationships exist between the endophyte and beech. Such studies might reveal patterns associating environmental conditions, such as drought, with reduced endophyte colonization, which in turn may influence disease severity. 
Table 3.1: A listing of cultural descriptions of fungal endophytes extracted from resistant (R) or susceptible (S) beech cambium in 2011. The association of R or S indicates the origin of the type specimen for each morphotype.

\begin{tabular}{|c|c|c|c|}
\hline Culture Code & $\begin{array}{l}\text { Resistant or } \\
\text { Susceptible? }\end{array}$ & Culture Description & $\begin{array}{l}\text { Microscopic } \\
\text { Description } \\
\end{array}$ \\
\hline RG_100 & $\mathrm{S}$ & $\begin{array}{l}\text { Dark brown } 2.5-3 \mathrm{~cm} \text {; very similar } \\
\text { to } R_{-}{ }_{1} 15\end{array}$ & $\begin{array}{l}\text { Hyaline, septate } \\
\text { hyphae with } \\
\text { circular } 12- \\
14 \mu \mathrm{m} \\
\text { chlamydospore- } \\
\text { like structures. }\end{array}$ \\
\hline RG_101 & $\mathrm{R}$ & $\begin{array}{l}\text { Reverse amber with sienna spots } \\
\text { irregularly scattered. Cottony-felty, } \\
\text { cream-golden mycelia, occasionally } \\
\text { nodulose. Fast growing. }\end{array}$ & $\begin{array}{l}\text { Very fine } \\
\text { hyphae with } \\
\text { clamps. }\end{array}$ \\
\hline RG_102 & $\mathrm{R}$ & & \\
\hline RG_103 & $\mathrm{R}$ & $\begin{array}{l}\text { Floccose-downy on top, reverse } \\
\text { dark grey-black. Very small and } \\
\text { slow growing. Mats free and } \\
\text { crusty. }\end{array}$ & $\begin{array}{l}\text { Very fine, } \\
\text { straight, yellow- } \\
\text { brown colored } \\
\text { hyphae. Chains } \\
\text { of spore-like } \\
\text { structures (3- } \\
5 \mu \mathrm{m}) \text {--possible } \\
\text { yeast. }\end{array}$ \\
\hline RG_104 & $\mathrm{S}$ & & \\
\hline RG_105 & $\mathrm{S}$ & $\begin{array}{l}\text { Reverse dark brown to black, } \\
\text { crusty. Brown-green to beige } \\
\text { velvety mycelia mound; small and } \\
\text { slow-growing }\end{array}$ & \\
\hline RG_106 & $\mathrm{R}$ & $\begin{array}{l}\text { Distinct, fimbriate colonies. Felty, } \\
\text { lime green to olive mycelia with } \\
\text { white, nodulose, tufty mycelia } \\
\text { along margin. Agar red pigmented, } \\
\text { possible Valsa. }\end{array}$ & $\begin{array}{l}\text { Hyphae fine and } \\
\text { hyaline, } \\
\text { sometimes } \\
\text { crimped or } \\
\text { ending in } \\
\text { bulbous-like } \\
\text { structures. }\end{array}$ \\
\hline
\end{tabular}




$\begin{array}{lll}\mathrm{RG}_{-} 107 & \mathrm{R} & \begin{array}{l}\text { vein or crack-like structures } \\ \text { winding through it, pink-grey } \\ \text { velvety mycelia in the center. }\end{array} \\ \mathrm{RG} \_108 & \mathrm{R} & \\ \mathrm{RG} \_109 & \mathrm{~S} & \begin{array}{l}\text { Reverse black, brown-grey mycelia, } \\ \text { raised. Crustose under and downy } \\ \text { on tops; mats are free. }\end{array}\end{array}$

RG_110 R

RG_111 S

RG_112 S

RG_113 S

RG_114 S

RG_115 S

RG_116 R

RG_117 S
Reverse bright orange-yellow. Fimbriate edges with node-like structures dispersed on top of colony. Short, brick, velvety mycelia in center.
Brick-sienna margins with thick, Long, slightly curved hyaline spores borne on $15 \mu \mathrm{m}$ phialides.

Regularly branching hyphae resembling roots. Olive to brown colored. Mount very difficult to squash.

Golden hyphae with chlamydosporelike structures.
Hyphae olive-

Reverse grey-black, dark-brown black fading to light olive shortcottony mycelia on top. Culture intersperced with dark black pycnidia-like structures and fluffy, white nodulose mycelia. colored, scaly. Large, tapered $(15 \times 9 \mu \mathrm{m})$ structures, possible spores found intermittently. 
Hyphae darkochre, irregularly tangled with occasional

Burnt sienna, silky and iridescent sporophores

RG_118 R on top. Reverse dark mauve with distinct dark sienna rings. Centers subfelty-downy and light brown.

perpendicular to hyphae on short phialides. Long curved spores $(7 \mu \mathrm{m})$; resembles

Phialophora (Barnett \& Hunter, pg. 89)

RG_119 S

RG_120 S

RG_121 S

RG $122 \quad \mathrm{R}$

RG_123 R

RG_124 S

RG_125 S

RG_126 R

RG_127 S

RG_128 S
Indistinct, slightly zonate hyaline mycelia. Margins fimbriate. Colony difficult to cut

Reverse burnt sienna fading to brown. Floccose grey-brown mycelia tufts on top of colony; fast growing
Sterile; hyaline, tangled hyphae without clamps.

Dark olive, septate, distinct hyphae. 
RG $129 \quad$ R

RG_130 R

RG_131 S

RG_132 S

RG_133 R

RG_134 S

RG_135 S
Appressed, hyaline to yellow mycelia, very fast growing; sterile. Very difficult to cut through.

Slow growing, sodden, indisctinct. Concentric rings of downy, burnt sienna in the center progressing to cream margins; zonate. $0.5-1 \mathrm{~cm}$ wide

Felty; hyaline to cream, fastgrowing mycelia.

Floccose, dark-beige hyphae interspersed between burnt sienna circles. Margins fimbriate, indistinct; colonies mounded.

Hyphae downy-velvety, dusty rose in the center surrounded by concentric rings of dark sienna and brown fading to olive-cream. $3 \mathrm{~cm}$ wide colony after 14 days; brown concentric rings culminating in a light beige velvety color in the center. Colonies zonate, even edged.

Zonate. Concentric rings of dark sienna in the center, olive and cream margins. Occasional white, tufty mycelia.
$5 \mu \mathrm{m}$

chlamydospores, with spirals of hyphae.

Sterile; amber colored, bulbous hyphae are arranged regularly in a linear fashion.

Sterile; possible arthrospores
Nodulose, amber-colored hyphae; sterile.
Dark olive, tortuous hyphae some forming angled connections; sterile. 
Agar yellow with hyaline mycelia.

RG_136 R

Many green perithecia scattered

over

mycelial mat.

RG_138 R

Slow growing, black and crusty.

Suspected Torula. 
Table 3.2: Identity and Frequency of Cultured Endophytes from BBD Resistant and Susceptible Beech (F. grandifolia). A listing of the morphotypes of endophytes extracted from beech cambium in 2011 and their identities. Identities were deduced using cultural descriptions and microscopy (indicated by "no ITS") followed by ITS sequencing if microscopy was insufficient. Frequency was calculated by dividing the number of times the particular isolate was observed in pure culture (n) versus the total number of unique pure cultures obtained from resistant and susceptible beech $(\mathrm{N}=86)$.

\begin{tabular}{|c|c|c|c|}
\hline $\begin{array}{l}\text { Morphotype } \\
\text { Code }\end{array}$ & Identity (ITS Sequence) & Frequency (Percentage) & $\mathrm{n}$ \\
\hline RG_136 & Chaetomium globosum & $9.30 \%$ & 8 \\
\hline $\mathrm{RG}_{-}^{-} 100$ & Unidentified & $6.98 \%$ & 6 \\
\hline $\mathrm{RG}_{-}^{-} 103$ & Neohendersonia kickxii & $6.98 \%$ & 6 \\
\hline $\mathrm{RG}_{-}^{-} 131$ & Fusarium cf. flocciferum & $6.98 \%$ & 6 \\
\hline $\begin{array}{l}\text { RG_139, } \\
\text { RG } 140\end{array}$ & Coniothyrium cf. fagi & $6.98 \%$ & 6 \\
\hline $\mathrm{RG}_{-}^{-} 115$ & Unidentified & $5.81 \%$ & 5 \\
\hline RG_101 & Coniophora puteana & $3.49 \%$ & 3 \\
\hline $\mathrm{RG}_{-}^{-} 109$ & Phaeosphaeriaceae sp. A & $3.49 \%$ & 3 \\
\hline $\mathrm{RG}_{-}^{-} 102$ & Unidentified & $2.33 \%$ & 2 \\
\hline $\mathrm{RG}_{-}^{-} 104$ & Phaeosphaeriaceae sp. B & $2.33 \%$ & 2 \\
\hline $\mathrm{RG}_{-}^{-} 107$ & Phaeoacremonium sp. & $2.33 \%$ & 2 \\
\hline $\mathrm{RG}_{-}^{-} 112$ & Neonectria faginata & $2.33 \%$ & 2 \\
\hline $\mathrm{RG}_{-} 118$ & Phialophora sp. (no ITS) & $2.33 \%$ & 2 \\
\hline $\mathrm{RG}_{-} 119$ & Unidentified & $2.33 \%$ & 2 \\
\hline $\mathrm{RG}_{-}^{-} 121$ & Unidentified & $2.33 \%$ & 2 \\
\hline \multirow{2}{*}{$\mathrm{RG}_{-} 134$} & Unidentified & & \\
\hline & Dothidiomycete & $2.33 \%$ & 2 \\
\hline RG_138 & Torula sp. (no ITS) & $2.33 \%$ & 2 \\
\hline $\mathrm{RG}_{-}^{-} 105$ & Unidentified & $1.16 \%$ & 1 \\
\hline RG_106 & Unidentified & $1.16 \%$ & 1 \\
\hline $\mathrm{RG}_{-} 108$ & Pleosporales sp. & $1.16 \%$ & 1 \\
\hline $\mathrm{RG}_{-}^{-} 110$ & Unidentified & $1.16 \%$ & 1 \\
\hline $\mathrm{RG}_{-} 111$ & Unidentified & $1.16 \%$ & 1 \\
\hline $\mathrm{RG}_{-}^{-} 113$ & Unidentified & $1.16 \%$ & 1 \\
\hline $\mathrm{RG}_{-}^{-} 114$ & Trametes versicolor & $1.16 \%$ & 1 \\
\hline $\mathrm{RG}_{-}^{-} 116$ & Unidentified & $1.16 \%$ & 1 \\
\hline $\mathrm{RG}_{-}^{-} 117$ & Unidentified & $1.16 \%$ & 1 \\
\hline $\mathrm{RG}_{-}^{-} 120$ & Unidentified & $1.16 \%$ & 1 \\
\hline RG_122 & Unidentified & $1.16 \%$ & 1 \\
\hline $\mathrm{RG}_{-}^{-} 123$ & Unidentified & $1.16 \%$ & 1 \\
\hline $\mathrm{RG}_{-}^{-} 124$ & Unidentified & $1.16 \%$ & 1 \\
\hline $\mathrm{RG}_{-}^{-} 125$ & Unidentified & $1.16 \%$ & 1 \\
\hline
\end{tabular}




\begin{tabular}{|c|c|}
\hline RG 126 & Unidentified \\
\hline $\mathrm{RG}_{-}^{-} 127$ & Unidentified \\
\hline $\mathrm{RG}_{-}^{-} 128$ & Unidentified \\
\hline $\mathrm{RG}^{-} 129$ & Unidentified \\
\hline $\mathrm{RG}^{-} 130$ & Unidentified \\
\hline $\mathrm{RG}^{-} 132$ & Unidentified \\
\hline $\mathrm{RG}^{-} 133$ & Unidentified \\
\hline $\mathrm{RG}_{-}^{-} 135$ & Unidentified \\
\hline $\mathrm{RG}^{-} 137$ & Unidentifi \\
\hline
\end{tabular}

$\begin{array}{ll}1.16 \% & 1 \\ 1.16 \% & 1 \\ 1.16 \% & 1 \\ 1.16 \% & 1 \\ 1.16 \% & 1 \\ 1.16 \% & 1 \\ 1.16 \% & 1 \\ 1.16 \% & 1 \\ 1.16 \% & 1\end{array}$


Table 3.3: Cellulose azure qualitative, visual rating from 0 (no cellulolytic activity) to 10 (strong cellulolytic activity) of beech endophytes and positive ( $P$. cinnabarinus, $C$. puteana) and negative (L. bicolor) controls. Ratings were recorded after nine and 18 days. Low numbers indicate low levels of cellulose azure dye liberation and subsequently low cellulase capability; high ratings indicate cellulase activity and prolific liberation of azure dye.

\begin{tabular}{|c|c|c|}
\hline Specimen ID & Nine-Day Rating & 18-Day Rating \\
\hline L. bicolor (DR 170) & 0 & 0 \\
\hline RG_103 (Neohendersonia kickxii) & 0 & 0 \\
\hline $\mathrm{RG}^{-} 01(N$. faginata $)$ & 0 & 3 \\
\hline $\mathrm{RG}_{-}^{-} 115$ & 0 & 3 \\
\hline $\mathrm{RG}_{-}^{-} 109$ & 0 & 0 \\
\hline $\mathrm{RG}_{-}^{-} 112$ (N. faginata) & 0 & 6 \\
\hline RG_104 (Phaeosphaeriaceae sp.) & 0 & 0 \\
\hline $\mathrm{RG}_{-}^{-} 121$ & 1 & 4 \\
\hline $\mathrm{RG}_{-}^{-} 113$ & 1 & 4 \\
\hline $\mathrm{RG}^{-} 131$ (Fusarium flocciferum) & 2 & 7 \\
\hline $\mathrm{RG}_{-}^{-} 136$ (Chaetomium globosum) & 2 & 8 \\
\hline $\mathrm{RG}_{-}^{-} 102$ & 3.5 & 10 \\
\hline $\mathrm{RG}^{-} 100$ & 4.5 & 7 \\
\hline $\mathrm{RG}_{-}^{-} 119$ & 5.5 & 8 \\
\hline P. cinnabarinus (DR_430) & 6 & 10 \\
\hline RG_114 (Trametes versicolor) & 7 & 10 \\
\hline RG_107 (Phaeoacremonium sp.) & 7 & 8 \\
\hline $\mathrm{RG}_{-}^{-} 101$ (Coniophora puteana) & 8 & 9 \\
\hline $\mathrm{RG}^{-} 118$ (Phialophora sp.) & 9 & 10 \\
\hline C. puteana (DR_460) & 10 & 10 \\
\hline
\end{tabular}



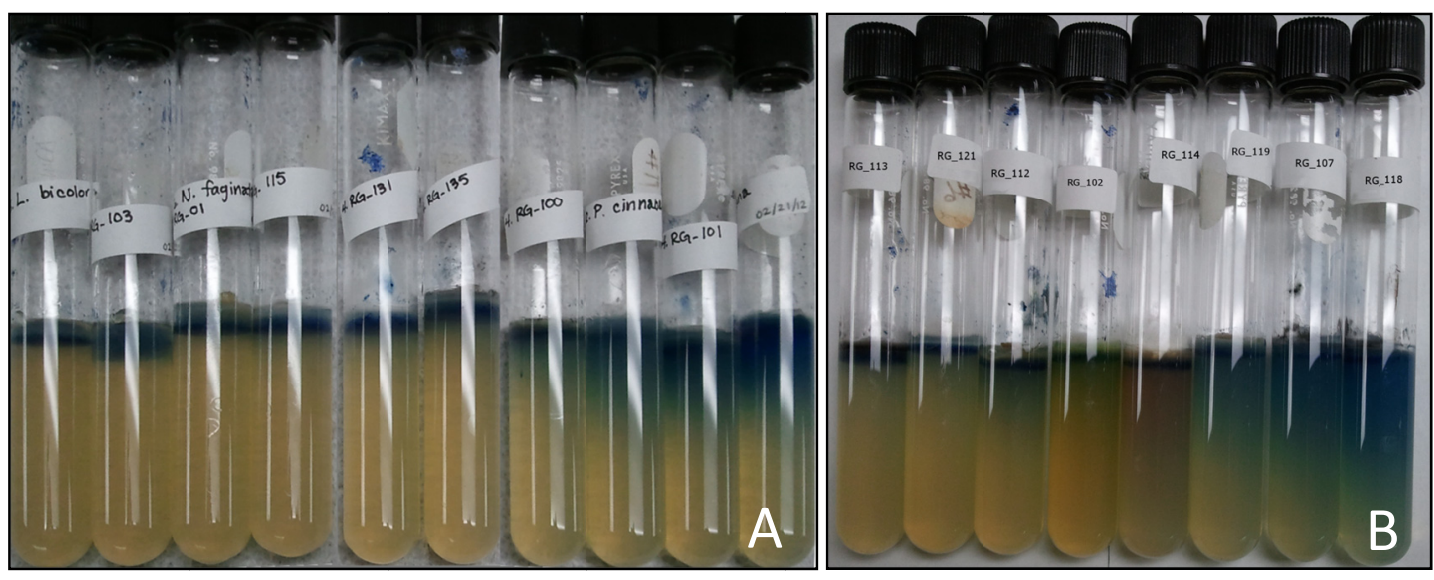

Figure 3.1: Visual Gradation of Cellulose Azure Dye Liberation. $A$, Cellulolytic activity rating after 9 days: 0 on left (tubes 1-4) to 10 on right. Positive controls are tube 8 and 10 ; negative control is tube $1 . B$, Cellulolytic activity rating of endophytes after 18 days: 4 on left (tubes $1 \& 2$ ) to 10 on right. 


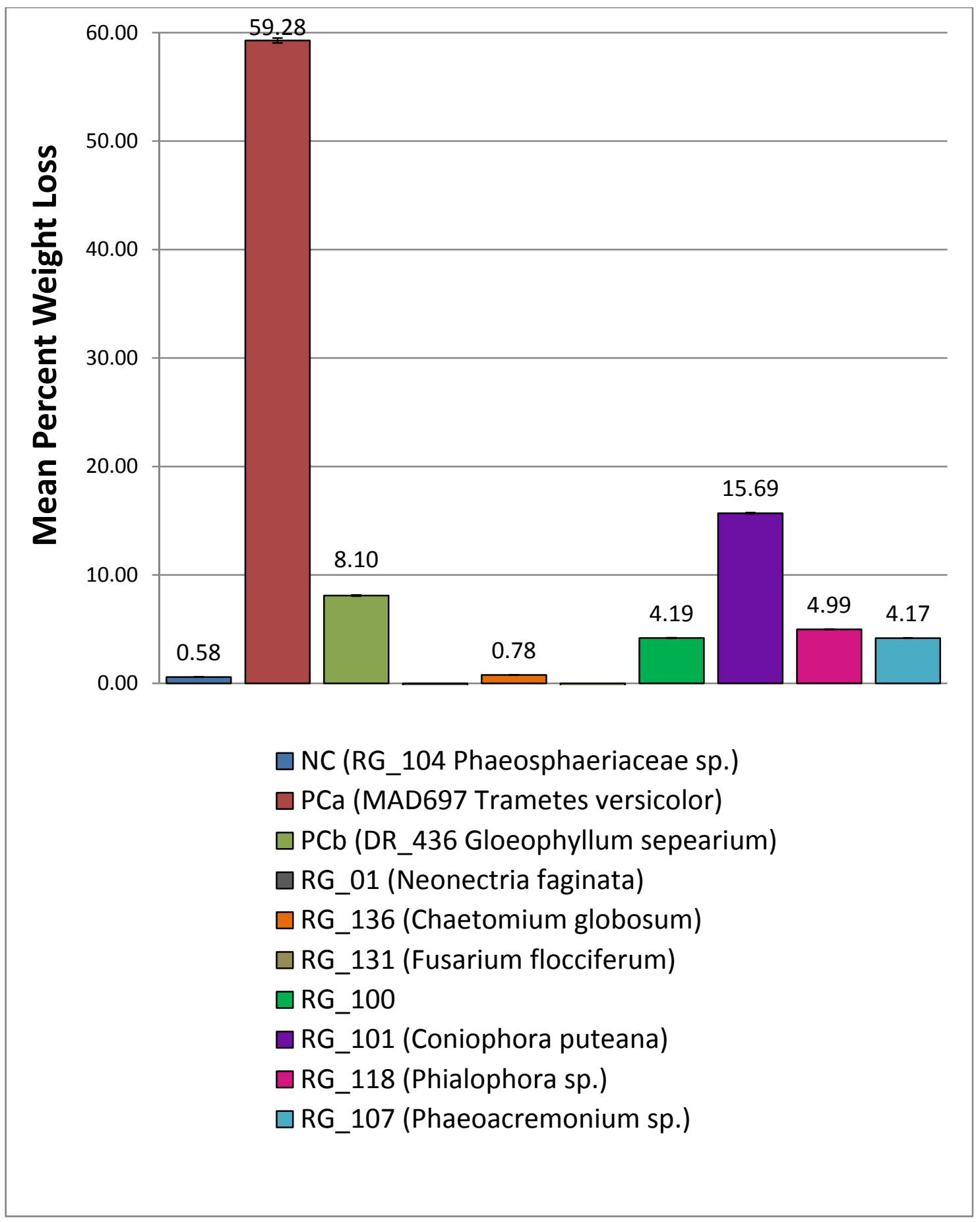

Figure 3.2: Mean percent weight loss caused by beech cambium endophytes following a 10 -week soil block decay test. Y-axis shows mean percent weight loss of beech endophytic fungi along with two positive controls, T. versicolor and G. sepearium and a negative control (RG_104). Mean percent weight loss of each isolate is displayed above the respective bar. Error bars represent standard error of the mean. 
Table 3.4: Results of multivariate one-way ANOVA and Scheffé's test of Neonectria antagonism by cambium-inhabiting endophytes of beech from 2011. Mean of maximum radial growth in mm of $N$. faginata is shown as affected by beech endophytes in vitro on $2 \%$ malt extract agar. Asterisked treatments in bold had a significant reduction in Neonectria radial growth compared to $N$. faginata pure culture growth after two weeks $(\mathrm{p}<0.001)$.

Mean \pm SE: Week $1 \quad$ Mean \pm SE: Week 2

Neonectria

C. globosum + Neonectria

C. puteana (RG_101) + Neonectria

Phaeosphaeriaceae sp. (RG_104)+ Neonectria

Phaeoacremonium sp. (RG_107)+ Neonectria

F. flocciferum (RG_131) + Neonectria

$17.33 \pm 0.72$

$$
15 \pm 0.72
$$$$
16.5 \pm 0.72
$$$$
17 \pm 0.72
$$

$16.83 \pm 0.72$

$18.17 \pm 0.72$

$34 \pm 0.61$

$15 \pm 0.61$ *

$19.67 \pm 0.61$ *

$$
33 \pm 0.61
$$

$29.67 \pm 0.61$

$28.33 \pm 0.61 *$ 


\section{Literature Cited}

Altschul, S.F., Madden, T.L., Schaffer, A.A., Zhang, J.H., Zhang, Z., Miller, W., Lipman, D.J., 1997. Gapped BLAST and PSI-BLAST: a new generation of protein database search programs. Nucleic Acids Res. 25, 3389-3402.

Archibald, F.S., 1992. A new assay for lignin-type peroxidases employing the dye azure B. Applied Environmental Microbiology 58, 3110-3116.

Baird, R.E., Watson, C.E., Woolfolk, S., 2007. Microfungi from bark of healthy and damaged American beech, fraser fir, and eastern hemlock trees during an all taxa biodiversity inventory in forests of the Great Smoky Mountains National Park. Southeastern Naturalist 6, 67-82.

Bier, J.E., Rowat, M.H., 1962. The relation of bark moisture to the development of canker diseases caused by native, facultative parasites. Canadian Journal of Botany 40, 61-69.

Bills, G.F., 1995. Analysis of microfungal diversity from a user's perspective. Canadian Journal of Botany 73, S33-S41.

Bills, G.F., Polishook, J.D., 1992. Recovery of endophytic fungi from Chamaecyparis thyoides. Sydowia 44, 01-12.

Brandt, R.W., 1964. Nectria canker on hardwoods. In: Agriculture, U.S.D.o. (Ed.). Northeastern Forest Experiment Station, New Haven, CT, pp. 1-7.

Carroll, G., 1988. Endophytes in stems and leaves: From latent pathogen to mutualistic symbiont. Ecology 69, 2-9. 
Carroll, G., 1995. Forest endophytes: pattern and process. Canadian Journal of Botany $73,1316-1324$.

Castlebury, L.A., Rossman, A.Y., Hyten, A.S., 2006. Phylogenetic relationships of Neonectria/Cylindrocarpon on Fagus in North America. Canadian Journal of Botany 84, 1417-1433.

Christensen, M.J., Latch, G.C.M., 1991. Variation among isolates of Acremonium endophytes (A. coenophialum and possibly A. typhinum) from tall fescue (Festuca arundinacea). Mycological Research 95, 1123-1126.

Cotter, H.V., Blanchard, R.O., 1982. The fungal flora of bark of Fagus grandifolia. Mycologia 74, 836-843.

Danti, R., Sieber, T.N., Sanguineti, G., 2002. Endophytic mycobiota in bark of European beech (Fagus sylvatica) in the Apennines. Mycological Research 106, 1343-1348.

Duncan, C.G., 1958. Studies of the methodology of soil-block testing. In. USDA Forest Service, pp. 1-126.

Fernandez, M.R., Boyer, M.G., 1989. Beech bark mycoflora and its distribution in relation to the presence of the scale insect, Cryptococcus fagisuga. Canadian Plant Disease Survey 69, 101-103.

Fisher, P.J., Petrini, O., 1990. A comparative study of fungal endophytes in xylem and bark of Alnus species in England and Switzerland. Mycological Research 94, 313319.

Fisher, P.J., Petrini, O., Petrini, L.E., Sutton, B.C., 1994. Fungal endophytes from the leaves and twigs of Quercus ilex L. from England, Majorca and Switzerland. New Phytologist 127, 133-137. 
Ganley, R.J., Sniezko, R.A., Newcombe, G., 2008. Endophyte-mediated resistance against white pine blister rust in Pinus monticola. Forest Ecology and Management 255, 2751-2760.

Gwiazdowski, R.A., Van Driesche, R.G., Desnoyers, A., Lyon, S., Wu, S.-a., Kamata, N., Normark, B.B., 2006. Possible geographic origin of beech scale, Cryptococcus fagisuga (Hemiptera: Eriococcidae), an invasive pest in North America. Biological Control 39, 9-18.

Heyd, R.L., 2005. Managing beech bark disease in Michigan. In: Evans, C.A., Lucas, J.A., Twery, M.J. (Eds.), Beech Bark Disease: Proceedings of the Beech Bark Disease Symposium, Saranac Lake, New York, pp. 128-132.

Hoffman, M.T., Arnold, A.E., 2008. Geographic locality and host identity shape fungal endophyte communities in cupressaceous trees. Mycol Res 112, 331-344.

Houston, D.B., Houston, D.R., 2000. Allozyme genetic diversity among Fagus grandifolia trees resistant or susceptible to beech bark disease in natural populations. Canadian Journal of Forest Research 30, 778-789.

Houston, D.R., 1983. American beech resistance to Cryptococcus fagisuga. In, I.U.F.R.O. Beech Bark Disease Working Party Conference. USDA Forest Service, Northeastern Forest Experiment Station. Gen. Tech. Rep. WO-37., Hamden, CT.

Houston, D.R., 1994a. Major new tree disease epidemics: Beech bark disease. Annual Review of Phytopathology 32, 75-87. 
Houston, D.R., 1994b. Temporal and spatial shift within the Nectria pathogen complex associated with beech bark disease of Fagus grandifolia. Canadian Journal of Forest Research 24, 960-968.

Houston, D.R., Parker, E.J., Perrin, R., Lang, K.J., 1979. Beech bark disease: A comparison of the disease in North America, Great Britain, France and Germany European Journal of Forest Pathology 9, 199-211.

Koch, J.L., Carey, D.W., Mason, M.E., Nelson, C.D., 2010. Assessment of beech scale resistance in full- and half-sibling American beech families. Canadian Journal of Forest Research 40, 265-272.

Krabel, D., Petercord, R., 2000. Genetic diversity and bark physiology of the European beech (Fagus sylvatica): A coevolutionary relationship with the beech scale (Cryptococcus fagisuga). Tree Physiology 20, 485-491.

Küffer, N., Lovas, P.S., Senn-Irlet, B., 2004. Diversity of wood-inhabiting fungi in natural beech forests in Transcarpathia (Ukraine): a preliminary survey. Mycologica Balcanica 1, 129-134.

Levi, M.P., Preston, R.D., 1965. A chemical and microscopic examination of the action of the soft-rot fungus Chaetomium globosum on beechwood (Fagus sylv.). Holzforschung 19, 183-190.

Martin, J.A., Witzell, J., Blumenstein, K., Rozpedowska, E., Helander, M., Sieber, T.N., Gil, L., 2013. Resistance to Dutch Elm Disease Reduces Presence of Xylem Endophytic Fungi in Elms (Ulmus spp.). PloS one 8, e56987. 
Miller, J.D., Mackenzie, S., Foto, M., Adams, G.W., Findlay, J.A., 2002. Needles of white spruce inoculated with rugulosin-producing endophytes contain rugulosin reducing spruce budworm growth rate. Mycological Research 106, 471-479.

O'Brien, J.G., Ostry, M.E., Mielke, M.E., Mech, R., Heyd, R.L., McCullough, D.G., 2001. First Report of Beech Bark Disease in Michigan. Plant Disease 85, 921921.

Park, J.H., Choi, G.J., Jang, K.S., Lim, H.K., Kim, H.T., Cho, K.Y., Kim, J.C., 2005. Antifungal activity against plant pathogenic fungi of chaetoviridins isolated from Chaetomium globosum. FEMS Microbiol Letters 252, 309-313.

Petrini, O., 1991. Fungal Endophytes of Tree Leaves. In: Andrews, J.H., Hirano, S.S. (Eds.), Microbial Ecology of Leaves. Springer New York, pp. 179-197.

Pointing, S.B., 1999. Qualitative methods for the determination of lignocellulolytic enzyme production by tropical fungi. Fungal Diversity 2, 17-33.

Ramirez, M., Loo, J., Krasowski, M.J., 2007. Evaluation of resistance to the beech scale insect (Cryptococcus fagisuga) and propagation of American beech (Fagus grandifolia) by grafting. Silvae Genetica 56, 163-169.

Rayner, A.D.M., Griffith, G.S., Wildman, H.G., 1994. Induction of metabolic and morphogenetic changes during mycelial interactions among species of higher fungi Biochemical Society Transactions 22, 389-394.

Rayner, A.D.M., Ramsdale, M., Watkins, Z.R., 1995. Origins and significance of genetic and epigenetic instability in mycelial systems. Canadian Journal of Botany 73, $1241-1248$. 
Richter, D.L., Zuellig, T.R., Bagley, S.T., Bruhn, J.N., 1989. Effects of red pine (Pinus resinosa Ait.) mycorrhizoplane-associated actinomycetes on in vitro growth of ectomycorrhizal fungi. Plant Soil 115, 109-116.

Sahashi, N., Kubono, T., Miyasawa, Y., Ito, S., 1999. Temporal variations in isolation frequency of endophytic fungi of Japanese beech. Canadian Journal of Botany 77, 197-202.

Schmidt, O., 2006. Wood and Tree Fungi: Biology, Damage, Protection, and Use. Springer-Verlag, Berlin, New York.

Schulz, B., Römmert, A.-K., Dammann, U., Aust, H.-J., Strack, D., 1999. The endophytehost interaction: a balanced antagonism? Mycological Research 103, 1275-1283.

Schulz, B., Wanke, U., Draeger, S., Aust, H.J., 1993. Endophytes from herbaceous plants and shrubs: effectiveness of surface sterilization methods. Mycological Research $97,1447-1450$.

Shigo, A.L., 1964. Organism interactions in the beech bark disease. Phytopathology 54, 263-269.

Smith, R.E., 1977. Rapid tube test for detecting fungal cellulase production. Applied and environmental microbiology 33, 980-981.

Speer, E.O., Butin, H., 1980. Is there a relationship between Dichanea rugosa and beech bark disease? Annals of Forest Science 37, 357-359.

Tehon, L.R., 1924. Notes on the Parasitic Fungi of Illinois. Mycologia 16, 135-142.

Toti, L., Viret, O., Chapela, I.H., Petrini, O., 1992. Differential attachment by conidia of the endophyte, Discula umbrinella (Berk. \& Br.) Morelet, to host and non-host surfaces. New Phytologist 121, 469-475. 
Unterseher, M., Schnittler, M., 2010. Species richness analysis and ITS rDNA phylogeny revealed the majority of cultivable foliar endophytes from beech (Fagus sylvatica). Fungal Ecology 3, 366-378.

Vicari, M. (Ed.), 1997. Endophytic Fungi in Grasses and Woody Plants. APS Press St Paul, Minnesota.

Wainhouse, D., Deeble, R., 1980. Variation in susceptibility of beech (Fagus spp.) to beech scale (Cryptococcus fagisuga). Annales des Sciences forestières 37, 279289.

Wang, C.J.K., Zabel, R.A., 1990. Identification manual for fungi from utility poles in the eastern United States. American Type Culture Collection, Rockville, Md.

Wieferich, D.J., McCullough, D.G., Hayes, D.B., Schwalm, N.J., 2011. Distribution of American beech (Fagus grandifolia) and beech scale (Cryptococcus fagisuga Lind.) in Michigan from 2005 to 2009. Northern Journal of Applied Forestry 28, 173-179.

Wilson, D., 2000. Microbial Endophytes. In: Bacon, C.W., White, J.F. (Eds.). CRC Press, p. 600 .

Worrall, J.J., Anagnost, S.E., Wang, C.J.K., 1991. Conditions for Soft Rot of Wood. Canadian Journal of Microbiology 37, 869-874.

Zar, J.H., 2010. Biostatistical Analysis, Fifth Edition. In: Lynch, D. (Ed.). Prentice Hall, Upper Saddle River, New Jersey. 